\title{
Vaccination with Alpha-Gal Protects Against Mycobacterial Infection in the Zebrafish Model of Tuberculosis
}

\author{
Iván Pacheco ${ }^{1,+}$, Marinela Contreras ${ }^{1,+}$, Margarita Villar ${ }^{1,2}{ }^{-}$, María Angeles Risalde ${ }^{3} \mathbb{C D}$, \\ Pilar Alberdi ${ }^{1} \oplus$, Alejandro Cabezas-Cruz ${ }^{4}\left(\mathbb{D}\right.$, Christian Gortázar ${ }^{1}$ and José de la Fuente ${ }^{1,5, *}$ \\ 1 SaBio Instituto de Investigación en Recursos Cinegéticos IREC-CSIC-UCLM-JCCM, Ronda de Toledo s/n, \\ 13005 Ciudad Real, Spain; ivan.pacheco@uclm.es (I.P.); marinela.contreras@uclm.es (M.C.); \\ MargaritaM.Villar@uclm.es (M.V.); maria.alberdi@uclm.es (P.A.); christian.gortazar@uclm.es (C.G.) \\ 2 Biochemistry Section, Faculty of Science and Chemical Technologies, and Regional Centre for Biomedical \\ Research (CRIB), University of Castilla-La Mancha, 13071 Ciudad Real, Spain \\ 3 Departamento de Anatomía y Anatomía Patológica Comparadas, Facultad de Veterinaria, Universidad de \\ Córdoba (UCO), Agrifood Excellence International Campus (ceiA3), 14071 Córdoba, Spain; \\ mariaa.risalde@uclm.es \\ 4 UMR BIPAR, INRAE, ANSES, Ecole Nationale Vétérinaire d'Alfort, Université Paris-Est, \\ 94700 Maisons-Alfort, France; cabezasalejandrocruz@gmail.com \\ 5 Department of Veterinary Pathobiology, Center for Veterinary Health Sciences, Oklahoma State University, \\ Stillwater, OK 74078, USA \\ * Correspondence: josedejesus.fuente@uclm.es \\ + These authors contributed equally.
}

Received: 24 March 2020; Accepted: 22 April 2020; Published: 24 April 2020

\begin{abstract}
The alpha-Gal syndrome (AGS) is associated with tick bites that can induce in humans high levels of IgE antibodies against the carbohydrate Gal $\alpha 1-3 \mathrm{Gal} \beta 1-(3) 4 \mathrm{GlcNAc}-\mathrm{R}(\alpha-\mathrm{Gal})$ present in glycoproteins and glycolipids from tick saliva that mediate primarily delayed anaphylaxis to mammalian meat consumption. It has been proposed that humans evolved by losing the capacity to synthesize $\alpha$-Gal to increase the protective immune response against pathogens with this modification on their surface. This evolutionary adaptation suggested the possibility of developing vaccines and other interventions to induce the anti- $\alpha-G a l$ IgM/IgG protective response against pathogen infection and multiplication. However, the protective effect of the anti- $\alpha-G a l$ immune response for the control of tuberculosis caused by Mycobacterium spp. has not been explored. To address the possibility of using vaccination with $\alpha$-Gal for the control of tuberculosis, in this study, we used the zebrafish-Mycobacterium marinum model. The results showed that vaccination with $\alpha$-Gal protected against mycobacteriosis in the zebrafish model of tuberculosis and provided evidence on the protective mechanisms in response to vaccination with $\alpha$-Gal. These mechanisms included B-cell maturation, antibody-mediated opsonization of mycobacteria, Fc-receptor (FCR)-mediated phagocytosis, macrophage response, interference with the $\alpha$-Gal antagonistic effect of the toll-like receptor 2 (TLR2)/nuclear factor kappa-light-chain-enhancer of activated B cells (NF-kB)-mediated immune response, and upregulation of pro-inflammatory cytokines. These results provided additional evidence supporting the role of the $\alpha$-Gal-induced immune response in the control of infections caused by pathogens with this modification on their surface and the possibility of using this approach for the control of multiple infectious diseases.
\end{abstract}

Keywords: alpha-Gal; vaccine; tuberculosis; vaccine; Mycobacterium; immunology 


\section{Introduction}

The alpha-Gal syndrome (AGS), which is now the focus of recent investigations, is associated with tick bites that can induce in humans high levels of $\operatorname{IgE}$ antibodies against the carbohydrate Gal $\alpha 1-3$ Gal $\beta 1-(3) 4 G l c N A c-R$ ( $\alpha$-Gal) present in glycoproteins and glycolipids from tick saliva that mediate delayed anaphylaxis to mammalian meat consumption and immediate anaphylaxis to tick bites, xenotransplantation, and certain drugs such as cetuximab [1-12]. Within the conflict and cooperation that drove the evolution of tick-host-pathogen interactions [13], humans evolved by losing the capacity to synthesize $\alpha$-Gal to increase the protective immune response against pathogens with this modification on their surface while increasing the risk to develop the AGS [6]. This evolutionary adaptation suggested the possibility of developing vaccines and other interventions to induce the anti- $\alpha-G a l$ IgM/IgG protective response against pathogen infection to prevent or control major infectious diseases worldwide [14-20].

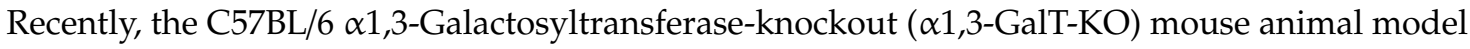
was used to study the antibody response to the carbohydrate $\alpha-\mathrm{Gal}$ and its potential for the control of infectious diseases such as malaria, leishmaniasis, Chagas disease, granulocytic anaplasmosis, and influenza caused by pathogens with this modification on their surface and/or by enhancing the protective immune response against these pathogens [15-22]. The results showed protection against pathogen infection in response to $\alpha$-Gal-containing vaccine formulations [15,18-22]. However, the protective effect of the anti- $\alpha-\mathrm{Gal}$ immune response for the control of tuberculosis caused by Mycobacterium spp. with $\alpha$-Gal on their surface [17] and constituting one of the deadliest infectious diseases worldwide [23] has not been explored.

To address the possibility of using vaccination with $\alpha$-Gal for the control of tuberculosis, in this study, we used the zebrafish Danio rerio (Hamilton, 1822) animal model. Zebrafish is a model organism for the study of immune mechanisms and new effective vaccines and control strategies against tuberculosis [24-28]. Additionally, zebrafish do not produce $\alpha$-Gal and were recently shown to reproduce some features of the human immune response to this molecule as a model for the study of the AGS [29]. The results of this study showed that vaccination with $\alpha$-Gal protects against mycobacterial infection in the zebrafish model of tuberculosis to further advance the possibility of developing a pan-vaccine for the simultaneous control of major infectious diseases worldwide [30]. Additionally, this vaccination strategy may be used for the control of fish mycobacteriosis or piscine tuberculosis affecting multiple freshwater and saltwater fish species and with human incidence worldwide [31].

\section{Materials and Methods}

\subsection{Ethics Statement}

Animal experiments were conducted in strict accordance with the recommendations of the European Guide for the Care and Use of Laboratory Animals. Animals were housed at and experiments were conducted at the experimental facility (IREC, Ciudad Real, Spain) with the approval and supervision of the Ethics Committee on Animal Experimentation of the University of Castilla La Mancha (PR-2018-06-13) and the Counseling of Agriculture, Environment, and Rural Development of Castilla La Mancha (ES130340000218).

\subsection{Flow Cytometry Analysis of Mycobacterium marinum $\alpha$-Gal Content}

The M. marinum Aronson (ATCC 927) was cultured at $29{ }^{\circ} \mathrm{C}$ in $7 \mathrm{H} 9$ broth enriched with Middlebrook ADC (Becton Dickinson, Franklin Lakes, NJ, USA). The bacteria were washed twice in phosphate-buffered saline (PBS), centrifuges at $4000 \mathrm{~g}$ for $5 \mathrm{~min}$, resuspended in PBS, fixed in $4 \%$ paraformaldehyde for $30 \mathrm{~min}$ at room temperature (RT), and washed once in PBS. The cells were incubated with 3\% human serum albumin (HAS; Sigma-Aldrich, St. Louis, MO, USA) in PBS for $1 \mathrm{~h}$ at RT. Then, cells were incubated for $14 \mathrm{~h}$ at $4{ }^{\circ} \mathrm{C}$ with the $\alpha$-Gal epitope (Gal $\left.\alpha 1-3 \mathrm{Gal} \beta 1-4 \mathrm{GlcNAc}-\mathrm{R}\right)$ monoclonal antibody (M86, Enzo Life Sciences, Farmingdale, NY, USA) diluted 1:50 in 3\% human serum 
albumin (HAS)/PBS. Fluorescein isothiocyanate (FITC)-goat anti-mouse IgM (Abcam, Cambridge, UK) labelled antibody (diluted 1/200 in 3\% HSA/PBS) was used as a secondary antibody and incubated for $1 \mathrm{~h}$ at RT. Samples were analyzed on a FAC-Scalibur flow cytometer equipped with CellQuest Pro software (BD Bio-Sciences, Madrid, Spain). The viable cell population was gated according to forward-scatter (FSC-H) and side-scatter (SSC-H) parameters. Aliquots of fixed and stained samples were used for immunofluorescence assays after air-drying and mounting in ProLong Antifade reagent containing 4',6-diamidino-2-phenylindole (DAPI) (Molecular Probes, Eugene, OR, USA). The sections were examined using a Zeiss LSM 800 laser scanning confocal microscope (Carl Zeiss, Oberkochen, Germany) with oil immersion objectives (63x).

\subsection{Zebrafish}

Wild-type adult (6- 8 months old) AB female and male zebrafish were kindly provided by Juan Galcerán Sáez from the Instituto de Neurociencias (IN-CSIC-UMH, Sant Joan d'Alacant, Alicante, Spain). These zebrafish were certified by Biosait Europe S.L. (Barcelona, Spain; https://biosait.com) as free of major fish pathogens such as Mycobacterium spp., Pseudoloma neurophilia, Pseudocapillaria tomentosa, and zebrafish retroviruses. The zebrafish were maintained in a flow-through water system at $27^{\circ} \mathrm{C}$ with a light/dark cycle of $14 \mathrm{~h} / 10 \mathrm{~h}$ and fed twice daily with dry fish feed (Premium food tropical fish, DAPC, Valladolid, Spain).

\subsection{Zebrafish Caccination With $\alpha$-Gal and Challenge with M. marinum}

\subsubsection{Experiment 1 (Figure 1A)}

This experiment was designed to evaluate the effect of vaccination with bovine serum albumin (BSA) coated with $\alpha$-Gal (BSA- $\alpha$-Gal, thereafter named $\alpha$-Gal; Dextra, Shinfield, UK) in combination with adjuvant Montanide ISA 71 VG (SEPPIC, Paris, France) and in comparison with BSA and adjuvant alone. For vaccine formulation, $\alpha-G a l$ was adjuvated as previously described [32] to a final concentration of $0.25 \mu \mathrm{g} / \mu \mathrm{l}$ in a vaccination dose volume of $20 \mu \mathrm{l}$. Fourteen fish were randomly allocated to vaccinated and control groups with a similar number of females and males. Fish were briefly anaesthetized by immersion in $0.02 \%$ tricaine methanesulfonate (MS-222) and vaccinated at weeks 0 (prime delivery) and 3 (boost delivery). Fish were vaccinated by intraperitoneal (IP) injection using a 30G insulin syringe with $50 \mu \mathrm{l}$ of antigen composition. The M. marinum Aronson (ATCC 927) was cultured at $29^{\circ} \mathrm{C}$ in $7 \mathrm{H} 9$ broth enriched with Middlebrook ADC (Becton Dickinson) and prepared for infection as previously described $[27,33]$. To verify the bacterial dose, $M$. marinum samples were diluted and plated on 7H10 agar enriched with Middelbrook OADC (Becton Dickinson) for counting bacterial colonies. Before challenge, fish were anaesthetized as described above and IP injected at week 5 with an infection dose equivalent to $50 \pm 8 \mathrm{cfu}$ of $M$. marinum, causing a chronic tuberculosis-like disease in zebrafish [27]. At week 8, fish were euthanized with immersion in $0.04 \%$ MS-222 and processed for analysis of antibody levels by ELISA, mycobacteria levels by qPCR, and expression of selected immune response gene markers by qRT-PCR. The zebrafish had weights of $333.0 \pm 133.6$ and $370.7 \pm 91.2 \mathrm{mg}$ at prime immunization and $344.2 \pm 122.2$ and $469.1 \pm 106.0 \mathrm{mg}$ at euthanasia for vaccinated and control groups, respectively.

\subsubsection{Experiment 2 (Figure 1B)}

In this experiment, the $\alpha$-Gal antigen was formulated without adjuvant and used in comparison with PBS for vaccination of zebrafish treated with IP injection and mucosal exposure to PBS or M. marinum or left untreated. For vaccine formulation, $\alpha$-Gal was diluted in PBS to a final concentration of $0.25 \mu \mathrm{g} / \mu \mathrm{l}$ in a vaccination dose volume of $20 \mu \mathrm{l}$. Controls were injected with a similar volume of PBS. A total of 87 fish were randomly allocated to uninfected/PBS, uninfected $/ \alpha-G a l$, vaccinated, and control groups with a similar number of females and males. Animals were vaccinated at weeks 0 and 3 as described in experiment 1 . Then, at week 5 and before treatment (T1), fish from each group were 
euthanized as described above. Remaining fish were subjected to the different treatments at week 5 and euthanized at week 8 as described in experiment 1 . These treatments included IP injection of PBS or M. marinum and mucosal exposure to PBS or M. marinum. IP injection was conducted as described above in experiment 1 . Mucosal treatment was conducted as described before by immersion for $30 \mathrm{~min}$ in $500 \mathrm{ml}$ water containing $56 \pm 6 \mathrm{cfu} / \mathrm{ml}$ of $\mathrm{M}$. marinum, while control animals were immersed in water with the same dose of PBS [28]. At week 8, fish were euthanized as described above in experiment 1 and processed for analysis of antibody levels by ELISA, granulomas by histopathology, mycobacteria levels by qPCR, proteome characterization by Sequential Windowed data independent Acquisition of the Total High-resolution Mass Spectra (SWATH), and expression of selected immune response gene markers by qRT-PCR (Figure 1B). The zebrafish had weights at prime immunization and euthanasia (T2), respectively, of $330.0 \pm 132.0$ and $345.9 \pm 124.8 \mathrm{mg}$ (PBS vaccination and treatment), $274.5 \pm 137.3$ and $357.9 \pm 170.8 \mathrm{mg}$ ( $\alpha$-Gal vaccination and no treatment), $258.3 \pm 97.6$ and $386.0 \pm 78.3 \mathrm{mg}(\alpha-\mathrm{Gal}$ vaccination and IP infection), $242.4 \pm 117.9$ and $323.4 \pm 110.1 \mathrm{mg}$ ( $\alpha$-Gal vaccination and mucosal infection), $279.4 \pm 107.3$ and $366.7 \pm 149.3 \mathrm{mg}$ (PBS vaccination and IP infection), and $340.4 \pm 115.3$ and $497.6 \pm 84.0 \mathrm{mg}$ (PBS vaccination and mucosal infection).

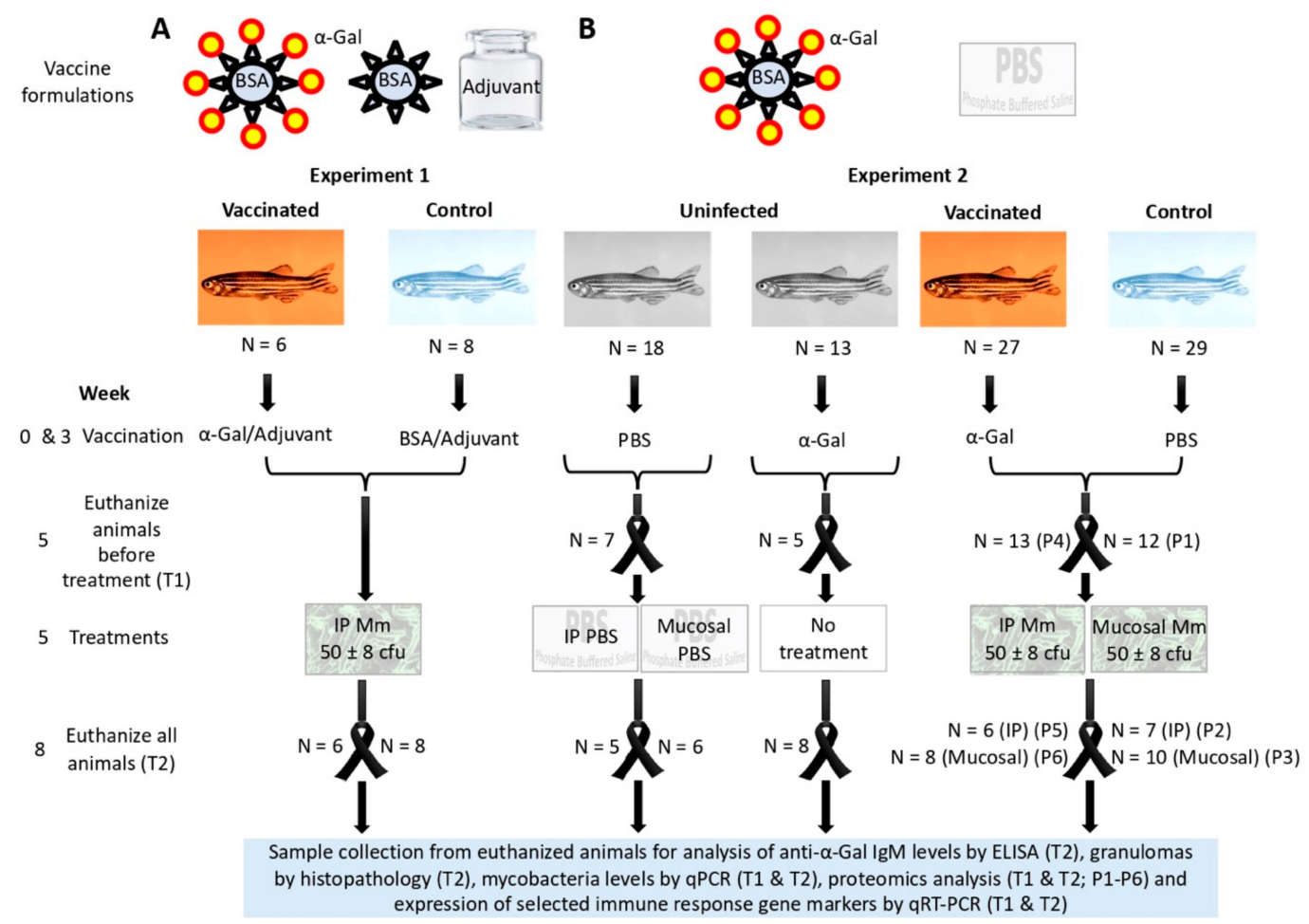

Figure 1. Experimental design: Two experiments were conducted to characterize the protective efficacy and mechanisms of vaccination with $\alpha$-Gal in zebrafish infected with M. marinum (Mm). (A) In experiment 1 , fish were parenterally (IP) vaccinated with $\alpha$-Gal or bovine serum albumin (BSA) control with adjuvant and IP infected with Mm. Samples were collected after vaccination and treatment with Mm or PBS at the end of the experiment (T2). (B) Experiment 2 was conducted with IP vaccination with $\alpha$-Gal without adjuvant in comparison with PBS-treated controls in fish infected with IP and mucosal Mm or left untreated. In experiment 2, samples were collected after vaccination and before treatment (T1) and at the end of the experiment (T2). Samples collected from euthanized fish were used for analysis of anti- $\alpha$-Gal IgM levels by ELISA (T2), granulomas by histopathology (T2), mycobacteria levels by qPCR (T1 and T2), proteomics analysis (T1 and T2; P1-P6), and expression of selected immune response gene markers by qRT-PCR (T1 and T2). 


\subsection{Anti- $\alpha$-Gal IgM Antibody Titers in Zebrafish}

For ELISA, high absorption capacity polystyrene microtiter plates were coated with $100 \mathrm{ng}$ of $\alpha$-Gal per well in carbonate-bicarbonate buffer (Sigma-Aldrich). After an overnight incubation at $4{ }^{\circ} \mathrm{C}$, coated plates were washed one time with $100 \mu \mathrm{l} /$ well PBS/1\% Triton X-100 (PBST) (Sigma-Aldrich), and then blocked with $100 \mu \mathrm{l} /$ well of 1\% HSA (Sigma-Aldrich) for $1 \mathrm{~h}$ at RT. A dilution curve with 1:10, 1:100, and 1:1000 fish serum peritoneal fluid samples was performed and then diluted $(1: 10, \mathrm{v} / \mathrm{v})$ in blocking solution, and $100 \mu \mathrm{l} /$ well was added into the wells of the antigen-coated plates and incubated for $1.5 \mathrm{~h}$ at $37^{\circ} \mathrm{C}$. Plates were washed three times with PBST and $100 \mu \mathrm{l} /$ well of species-specific rabbit anti-zebrafish IgM antibodies diluted $(1: 1000, v / v)$ in blocking solution were added and incubated for $1 \mathrm{~h}$ at RT. Plates were washed three times with $300 \mu \mathrm{l} /$ well of PBST. A goat anti-rabbit IgG-peroxidase conjugate (Sigma-Aldrich) was added diluted 1:3000 in blocking solution and incubated for $1 \mathrm{~h}$ at RT. After four washes with $100 \mu \mathrm{l} /$ well of PBST, $100 \mu \mathrm{l} /$ well of 3,3',5,5'-Tetramethylbenzidine (TMB) (Promega, Madison, WI, USA) was added and incubated for $15 \mathrm{~min}$ at RT. Finally, the reaction was stopped with $50 \mu \mathrm{l} /$ well of $2 \mathrm{~N} \mathrm{H}_{2} \mathrm{SO}_{4}$ and the optical density (OD) was measured in a spectrophotometer at $450 \mathrm{~nm}$. The OD at $450 \mathrm{~nm}$ was compared between different groups by Student's $t$-test with unequal variance ( $p<0.05$; experiment $1, n=6$ for vaccinated fish and $n=8$ for controls; experiment $2, n=6$ for fish vaccinated and IP M. marinum, $n=8$ for fish vaccinated and mucosal $M$. marinum, $n=7$ for controls and IP M. marinum, and $n=10$ for controls and mucosal M. marinum).

\subsection{Histopathology}

The analysis was conducted in animals collected from experiment 2 (Figure 1B). Zebrafish were sectioned sagittally, and half of them were immediately fixed in $10 \%$ neutral buffered formalin for $24 \mathrm{~h}$ at $21^{\circ} \mathrm{C}$, dehydrated in a graded series of ethanol, immersed in xylol, and embedded in paraffin wax using an automatic processor. Sections were cut at $4 \mu \mathrm{m}$ and stained with haematoxylin and eosin (HE) and Ziehl-Neelsen (ZN) staining following standard procedures $[27,28]$. The small size of the zebrafish and the sagittal sections to divide them in two portions for molecular and histopathological studies permitted a histological assessment only in central nervous system, branchial arches, muscle, skin, liver, intestine, and gonads. Tuberculous granulomas were evaluated and classified according to their components (a) in early granuloma composed of an epithelioid macrophages infiltrate positive to mycobacteria and without or early necrosis and (b) in mature granuloma well-organized and infiltrated of epithelioid macrophages with areas of partial and complete central necrosis and acid-fast bacilli and insulated from the surrounding tissue by a fibrotic and/or cellular cuff. The quantitative assessment of the granulomas consisted of identifying and counting the organs with granulomas per zebrafish. Pathological findings were graded by a numerical score based on the number of granulomas, the type of granulomas, and the number of regions and/or organs involved by granulomatous disease in each fish. Histopathology and ZN staining for mycobacteria were used for the quantification of granuloma lesion scores in the studied organs. The granuloma lesion scores were compared between groups by Student's $t$-test with unequal variance and by a one-way ANOVA test (https://www.socscistatistics.com/tests/anova/default2.aspx) and the number of early tuberculosis-like granulomas with epithelioid macrophages infiltrates surrounding scattered mycobacteria, and well-organized granulomas with partial and complete necrosis were compared between $\alpha$-Gal vaccinated and not vaccinated zebrafish by Student's t-test with unequal variance $(p=0.05 ; n=5$ for fish PBS vaccinated and IP PBS, $n=6$ for fish PBS vaccinated and mucosal PBS, $n=7$ for fish $\alpha$-Gal vaccinated and untreated, $n=5$ for fish vaccinated and IP M. marinum, $n=8$ for fish vaccinated and mucosal M. marinum, $n=7$ for controls and IP M. marinum, and $n=9$ for controls and mucosal M. marinum).

\subsection{Extraction of Total DNA, RNA, and Proteins from Zebrafish}

Total DNA, RNA, and proteins were isolated from the intestine of euthanized fish using the AllPrep DNA/RNA/Protein (Qiagen, Hilden, Germany). 


\subsection{Characterization of M. marinum DNA Levels by qPCR}

The DNA levels of $M$. marinum were determined by qPCR using the KAPA SYBR FAST one-step universal kit (Sigma-Aldrich) in the Rotor-Gene Q (Qiagen, Inc. Valencia, CA, USA) thermocycler following manufacturer's recommendations with specific primers and conditions for M. marinum $16 S$ ribosomal RNA (16S rRNA; Genbank accession number: AF456240.1) (16SForward-F: 5'-ACTGAGATACGGCCCAGACT-3', 16SReverse-R: 5' - TCACGAACAACGCGACAAAC-3', annealing $56^{\circ} \mathrm{C}, 30 \mathrm{sec}$ ). A dissociation curve was run at the end of the reactions to ensure that only one amplicon was formed and that the amplicon denatured consistently in the same temperature range for every sample [34]. The DNA Ct values were normalized against D. rerio glyceraldehyde-3-phosphate dehydrogenase (gapdh; NM_001115114.1) (GAPDHF: 5'-CGTGGTGCCAGTCAGAACAT-3', GAPDHR: 5'-AGTCAGTGGACACAACCTGG-3', annealing $56^{\circ} \mathrm{C}, 30 \mathrm{sec}$ ) using the genNormddCT method [35]. M. marinum DNA-normalized Ct levels were compared between groups by Student's $t$-test with unequal variance $(p=0.05$; experiment $1, n=6$ for vaccinated fish, $n=8$ for controls; experiment 2 at T2, $n=6$ for fish vaccinated and IP M. marinum, $n=8$ for fish vaccinated and mucosal M. marinum, $n=7$ for controls and IP M. marinum, and $n=10$ for controls and mucosal M. marinum; experiment 2 at T1 vs. T2, $n=7$ for PBS vaccinated uninfected fish, $n=5$ for $\alpha$-Gal vaccinated uninfected fish, $n=13$ for $\alpha$-Gal vaccinated infected fish, $n=12$ for PBS vaccinated infected fish and T2, $n=5$ for fish PBS vaccinated and IP PBS, $n=6$ for fish PBS vaccinated and mucosal PBS, $n=8$ for fish $\alpha$-Gal vaccinated and untreated, $n=6$ for fish vaccinated and IP M. marinum, $n=8$ for fish vaccinated and mucosal M. marinum, $n=7$ for controls and IP M. marinum, and $n=10$ for controls and mucosal M. marinum). A Spearman's Rho correlation analysis (https://www.socscistatistics.com/tests/spearman/Default2.aspx) was performed between normalized M. marinum DNA levels and anti- $\alpha$-Gal IgM antibody levels (experiment $1, n=6$ for vaccinated fish, $n=8$ for controls, $\rho=-0.565$, two-tailed $p=0.03$; experiment $2, n=14$ for $\alpha$-Gal vaccinated fish and IP/mucosal infection at T2, $\rho=-0.515$, two-tailed $p=0.004$, $n=17$ for PBS controls and IP/mucosal infection at T2, $n=6$ for $\alpha$-Gal vaccinated fish and IP infection at T2, $n=7$ for PBS controls and IP infection at T2, $\rho=-0454$, two-tailed $p=0.12$, and $n=8$ for $\alpha$-Gal vaccinated fish and mucosal infection at T2, $n=10$ for PBS controls and mucosal infection at T2, $\rho=-0522$, two-tailed $p=0.03)$.

\subsection{Characterization of $m R N A$ Levels of Selected Zebrafish Immune Response Genes by qRT-PCR}

To characterize the expression of selected genes previously shown to be involved in vaccine protective mechanisms [36] and/or fish immune response to infection [37], a qRT-PCR was performed for the analysis of $D$. rerio tumor necrosis factor-alfa (tnf alpha; NM_212859.2), chemokine receptor type $4 a$ (cxcr4a; NM_131882.3), chemokine receptor 6a (ccr6a; NM_001099991.1), toll-like receptor 2 (TLR2; NM_212812.1), toll-like receptor 4 (TLR4; NM_001328605), interleukin 1-beta (IL-1 $;$; NM_212844.2), akirin 1 (akr1; NM_001007186.2), akirin 2 (akr2; NM_213294.2), and complement component 3 (C3; NM_131243.1) genes in zebrafish in response to vaccination and mycobacterial infection. The qRT-PCR was performed using the KAPA SYBR FAST one-step universal kit (Sigma-Aldrich) in the Rotor-Gene $Q$ (Qiagen) with specifics forward $(F)$ and reverse $(R)$ primers and conditions following manufacturer's recommendations (Table 1). A dissociation curve was run at the end of the reactions to ensure that only one amplicon was formed and that the amplicon denatured consistently in the same temperature range for every sample [34]. The mRNA Ct values were normalized against $D$. rerio gapdh as described above for the qPCR using the genNormddCT method [35]. The mRNA-normalized Ct values were compared between groups by Student's $t$-test with unequal variance $(p=0.05)$ and then represented as the ratio between normalized Ct values in fish $\alpha$-Gal-vaccinated and PBS control IP infected with M. marinum at T2 ( $n=6$ for fish $\alpha$-Gal vaccinated and $n=7$ for controls), the ratio between normalized $\mathrm{Ct}$ values in fish $\alpha$-Gal-vaccinated and PBS control with mucosal infection with M. marinum at T2 $(n=8$ for fish $\alpha$-Gal vaccinated and $n=10$ for controls), and the ratio between normalized Ct values at T1 and T2 (T1, $n=7$ for PBS vaccinated uninfected fish, $n=5$ for $\alpha$-Gal vaccinated uninfected fish, $n=13$ for $\alpha$-Gal vaccinated infected fish, $n=12$ for PBS vaccinated infected fish; T2, $n=5$ for fish PBS vaccinated and IP 
PBS, $n=6$ for fish PBS vaccinated and mucosal PBS, $n=8$ for fish $\alpha$-Gal vaccinated and untreated, $n=6$ for fish $\alpha$-Gal vaccinated and IP M. marinum, $n=8$ for fish $\alpha-$ Gal vaccinated and mucosal M. marinum, $n=7$ for controls and IP M. marinum, and $n=10$ for controls and mucosal M. marinum).

Table 1. Oligonucleotide primer sequences and annealing conditions.

\begin{tabular}{|c|c|c|}
\hline Gene & Oligonucleotide Primers & Annealing Conditions \\
\hline tnf alpha & $\begin{array}{l}\text { F: 5'-GCTTATGAGCCATGCAGTGA-3' } \\
\text { R: 5'-TGCCCAGTCTGTCTCCTTCT-3' }\end{array}$ & $56^{\circ} \mathrm{C}, 30 \mathrm{sec}$ \\
\hline ccr6a & $\begin{array}{l}\text { F: 5'-AGCTTCTGCGTGGCATCTAT-3' } \\
\text { R: 5'-CAGACGGCTGCACAAACTAA-3' }\end{array}$ & $56{ }^{\circ} \mathrm{C}, 30 \mathrm{sec}$ \\
\hline TLR4 & $\begin{array}{l}\text { F: 5'-TCACCTGGACAGCAAGAATG-3' } \\
\text { R: 5'-CGATTGACTTCCCTGCTTGA-3' }\end{array}$ & $56^{\circ} \mathrm{C}, 30 \mathrm{sec}$ \\
\hline$I L-1 \beta$ & $\begin{array}{l}\text { F: 5'-GCATGTCCACATATGCGTCG-3' } \\
\text { R: 5'-GCTGGTCGTATCCGTTTGGA-3' }\end{array}$ & $58^{\circ} \mathrm{C}, 30 \mathrm{sec}$ \\
\hline$a k r 1$ & $\begin{array}{l}\text { F: 5'-AGTTTGAGGCCCTTCTCAGC-3' } \\
\text { R: 5'-AAGTGCCTTCATGTCTGGGG-3' }\end{array}$ & $58^{\circ} \mathrm{C}, 30 \mathrm{sec}$ \\
\hline TLR2 & $\begin{array}{l}\text { F: 5'-TGAATGGGTCGAGGAGATTC-3' } \\
\text { R: 5'-CACAAAGTGCTCCGACAGAA-3' }\end{array}$ & $56^{\circ} \mathrm{C}, 30 \mathrm{sec}$ \\
\hline $\operatorname{cxcr} 4 a$ & $\begin{array}{l}\text { F: 5'-TGTACAGCAGCGTCCTCATC-3' } \\
\text { R: 5'-ACCCAGGTGACAAACGAGTC-3' }\end{array}$ & $58^{\circ} \mathrm{C}, 30 \mathrm{sec}$ \\
\hline C3 & $\begin{array}{l}\text { F: 5'-ACGCTCTCTGGATTGAAACA-3' } \\
\text { R: 5'-TGCCTTCTTGCATGGCAATC-3' }\end{array}$ & $56^{\circ} \mathrm{C}, 30 \mathrm{sec}$ \\
\hline$a k r 2$ & $\begin{array}{l}\text { F: 5'-ACTATGGACTTCGATCCGCT-3' } \\
\text { R: 5'-GCTCTGTGGTGAGTGCTGAA-3' }\end{array}$ & $56^{\circ} \mathrm{C}, 30 \mathrm{sec}$ \\
\hline
\end{tabular}

\subsection{Characterization of Zebrafish Proteome in Response to Vaccination and Infection}

Isolated proteins were resuspended in $10 \mathrm{mM}$ PBS with $2 \%$ SDS and protein concentration was determined using the BCA Protein Assay (Thermo Scientific) using bovine serum albumin (BSA) as standard. Proteins (100 $\mu \mathrm{g}$ per sample) were methanol/chloroform precipitated; resuspended in $30 \mu \mathrm{l}$ $50 \mathrm{mM}$ Tris- $\mathrm{HCl} \mathrm{pH}$ 7.5, 2\% SDS, $50 \mathrm{mM}$ dithiothreitol (DTT); and boiled for $5 \mathrm{~min}$ at $95 \mathrm{C}$. Proteins were trypsin digested using the filter aided sample preparation (FASP) protocol using the FASP Protein Digestion Kit (Expedeon, San Diego, CA, USA) following manufacturer recommendations. The resulting peptides were desalted onto OMIX Pipette tips C18 (Agilent Technologies), dried-down; and stored at $-20^{\circ} \mathrm{C}$ until mass spectrometry analysis (MS) by SWATH-MS.

\subsubsection{Proteome Analysis by SWATH-MS}

The desalted protein digests were resuspended in 2\% acetonitrile and 5\% acetic acid in water and analyzed by reverse phase liquid chromatography mass spectrometry (RP-LC-MS/MS) using an ekspertTM nanoLC 415 system coupled on line with a 6600 TripleTOF ${ }^{\circledR}$ mass spectrometer (AB SCIEX; Framingham, MA, USA) through Information-Dependent Acquisition (IDA) followed by SWATH. Four micrograms of each protein digest of the different control and vaccinated groups from experiment 2 (four animals per group) were used for the generation of the reference spectral ion library as part of SWATH-MS analysis. The peptides were concentrated using a $0.1 \times 20 \mathrm{~mm} \mathrm{C18} \mathrm{RP} \mathrm{precolumn} \mathrm{(Thermo}$ Scientific), and then separated using a $0.075 \times 250 \mathrm{~mm}$ C18 RP column (New Objetive, Woburn, MA, USA) operating at $0.3 \mathrm{ml} / \mathrm{min}$. Peptides were eluted using a 120 -min gradient from $5 \%-30 \%$ solvent $\mathrm{B}$ in solvent A followed by $15-\mathrm{min}$ gradient from $30 \%-60 \%$ solvent B in solvent A (Solvent A: $0.1 \%$ formic acid in water, solvent $\mathrm{B}: 0.1 \%$ formic acid in acetonitrile) and directly injected into the mass spectrometer for analysis. For IDA experiments, the mass spectrometer was set to scanning full spectra (350-1400 m/z) using $250 \mathrm{~ms}$ accumulation time per spectrum, followed by up to $50 \mathrm{MS} / \mathrm{MS}$ scans 
$(100-1500 \mathrm{~m} / \mathrm{z})$. Candidate ions with a charge state between +2 and +5 and counts per second above a minimum threshold of 100 were isolated for fragmentation. One MS/MS spectrum was collected for $100 \mathrm{~ms}$, before adding those precursor ions to the exclusion list for $15 \mathrm{sec}$ (mass spectrometer operated by Analyst TF 1.7; ABSciex). Dynamic background subtraction was turned off. MS/MS analyses were recorded in high-sensitivity mode with rolling collision energy on and a collision energy spread of 5. For SWATH quantitative analysis, twenty-two independent samples (four biological replicates from each PBS-vaccinated and $\alpha$-Gal-vaccinated fish without treatment and with mucosal and IP M. marinum in experiment 2; Figure 1B) $(8 \mu \mathrm{g}$ each) were subjected to the cyclic data independent acquisition (DIA) of mass spectra using the SWATH variable windows calculator (V 1.0, AB SCIEX) and the SWATH acquisition method editor (AB SCIEX), similar to previously established methods [38]. A set of 50 overlapping windows was constructed (containing $1 \mathrm{~m} / \mathrm{z}$ for the window overlap), covering the precursor mass range of 400-1250 m/z. For these experiments, a 50 -ms survey scan $(350-1400 \mathrm{~m} / \mathrm{z})$ was acquired at the beginning of each cycle and SWATH-MS/MS spectra were collected from 100-1500 m/z for $70 \mathrm{~ms}$ at high-sensitivity mode, resulting in a cycle time of $3.6 \mathrm{sec}$. Collision energy for each window was determined according to the calculation for a charge +2 ion-centered upon the window with a collision energy spread of 15 .

\subsubsection{Library Generation/Protein Identification, Data Processing, and Relative Quantitation}

To create a spectral library of all the detectable peptides in the samples, the IDA MS raw files were combined and subjected to database searches in unison using ProteinPilot software v. 5.0.1 (AB SCIEX) with the Paragon algorithm [39]. Spectra identification was performed by searching against the Danio rerio Uniprot database (62,016 entries in February 2020) with the following parameters: iodoacetamide cysteine alkylation, trypsin digestion, identification focus on biological modification, and thorough ID as search effort. The detected protein threshold was set at 0.05. An independent False Discovery Rate (FDR) analysis, using the target-decoy approach provided by Protein Pilot (AB SCIEX), was used to assess the quality of identifications. Positive identifications were considered when identified proteins reached a 1\% global FDR. For SWATH processing, up to 10 peptides with seven transitions per protein were automatically selected by the SWATH Acquisition MicroApp 2.0 in the PeakView 2.2 software (AB SCIEX) with the following parameters: 15 ppm ion library tolerance, 5 min extracted-ion chromatogram (XIC) extraction window, 0.01 Da XIC width, and considering only peptides with at least $99 \%$ confidence and excluding those which were shared or contained modifications. However, to ensure reliable quantitation, only proteins which had 3 or more peptides available for quantitation were selected for XIC peak area extraction and exported for analysis in the MarkerView 1.3 software (AB SCIEX). Global normalization was performed according to the total area sums of all detected proteins in the samples. In order to identify proteins that were significantly differentially represented between samples, a Student's $t$-test $(p=0.05)$ was used to perform two-sample comparisons between the averaged area sums of all the transitions derived for each protein across the four replicate runs for each sample under comparison. Gene ontology (GO) annotations were obtained using the Blast2GO software (http://www.blast2go.org). Raw proteomics data was deposited at the PeptideAtlas repository (http://www.peptideatlas.org/) with the dataset identifier PASS01545.

\section{Results}

\subsection{Experimental Design and Rationale}

The experimental design used in this study addressed the protective efficacy of vaccination with $\alpha$-Gal for the control of mycobacterial infection in the zebrafish model of tuberculosis using adjuvated (experiment 1; Figure 1A) and not adjuvated (experiment 2; Figure 1B) vaccine formulations. The rationale for using zebrafish is supported by constituting a validated model for tuberculosis [24-28] and the role of this species as an animal model for the study of the AGS [29]. The main objectives of the study were to characterize the effect of vaccination with $\alpha$-Gal on mycobacterial infection 
and the immune mechanisms putatively involved in vaccine efficacy. To address these objectives, vaccinated and control zebrafish were infected with $\alpha$-Gal-positive M. marinum [17], treated with PBS via IP or mucosal routes, or left untreated. Fish samples collected before and after treatment with M. marinum or PBS were used for analysis of IgM antibody levels by ELISA, granulomas by histopathology, mycobacteria levels by qPCR, proteomics analysis and expression of selected immune response gene markers by qRT-PCR (Figure 1A,B).

\subsection{Zebrafish Antibody Response to Vaccination with $\alpha$-Gal Correlates with Reduction in Mycobacterial Infection}

In experiment 1 (Figure 1A), the anti- $\alpha$-Gal IgM antibody levels significantly $(p=0.02)$ increased after vaccination with adjuvated $\alpha-G a l$ vaccine formulation when compared to controls (Figure 2A,B). The analysis of M. marinum DNA levels by qPCR showed a significant $(p=0.04)$ decrease in vaccinated when compared to control zebrafish (Figure 2C). A significant negative correlation $(p=0.03$ ) was obtained between M. marinum DNA levels and anti- $\alpha$-Gal IgM antibody titers (Figure 2D), thus providing evidence for the role of antibody response against $\alpha$-Gal in the control of mycobacteriosis in vaccinated fish. In experiment 2 (Figure 1B), the results also showed a significant increase in the anti- $\alpha$-Gal IgM antibody levels in both mucosal $(p=0.004)$ and IP $(p=0.02)$-infected zebrafish when compared to controls (Figure 3A). The antibody response increased after vaccination (week 5, T1; $p=0.01$ ) and remained higher than in untreated zebrafish (T0) until week 8 (T2; $p=0.004$ ) (Figure 3B). The M. marinum DNA levels significantly increased after infection (T1 vs T2) only in unvaccinated PBS-treated and untreated control zebrafish for both mucosal $(p=0.04)$ and IP $(p=0.01)$ infection routes (Figure 3C). These results translated into a significant decrease in M. marinum DNA levels in $\alpha$-Gal-vaccinated zebrafish when compared to controls infected via mucosal $(p=0.001)$ or IP $(p=0.002)$ routes (Figure 3D). As in experiment 1 but with a larger number of animals, a significant negative correlation ( $p=0.004)$ was obtained between M. marinum DNA levels and anti- $\alpha$-Gal IgM antibody titers (Figure 3E), thus providing additional support for the protective role of anti- $\alpha$-Gal antibody response against mycobacterial infection in zebrafish.

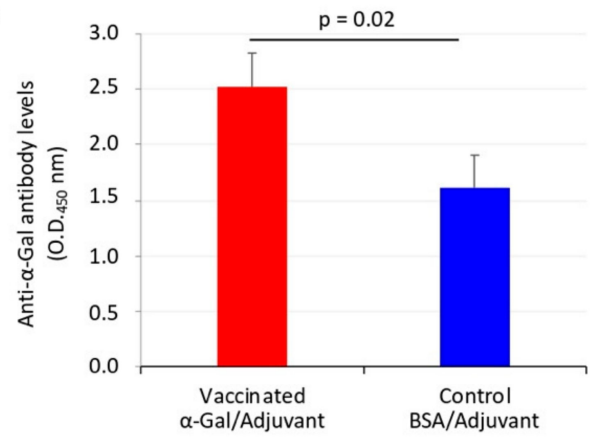

C

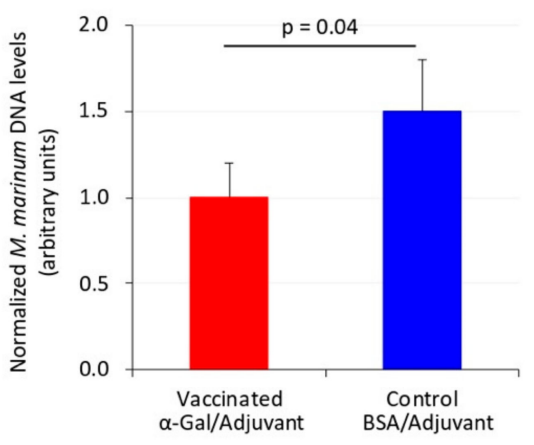

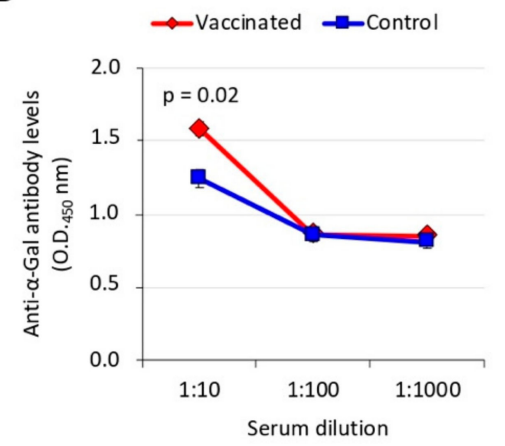

D

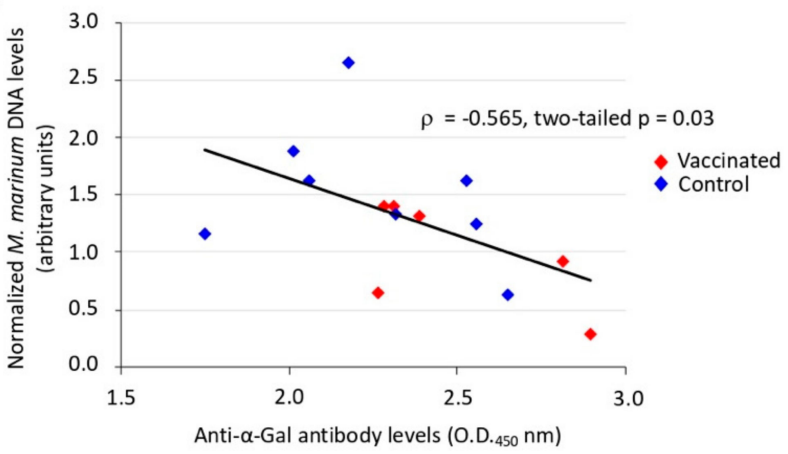

Figure 2. Experiment 1, effect of vaccination on the antibody response and mycobacterial infection 
levels in zebrafish. (A) The IgM antibody titers against $\alpha$-Gal were determined by ELISA in fish vaccinated with adjuvated $\alpha$-Gal or BSA alone as control and challenged with IP M. marinum. Antibody titers in vaccinated and control fish were represented as the average $+\mathrm{SD}$ of the $\mathrm{OD}_{450 \mathrm{~nm}}\left(\mathrm{OD}_{\text {antigen }}-\right.$ OD $P_{\text {PBS control }}$ ), and the mean of the duplicate values were compared between vaccinated and control groups by Student's $t$-test with unequal variance $(p<0.05)$. (B) ELISA dilution curve for IgM antibody titers against $\alpha$-Gal in fish vaccinated with adjuvated $\alpha$-Gal or BSA alone as control and challenged with M. marinum. Antibody titers were determined, represented, and analyzed as in (A) $(p<0.05)$. (C) M. marinum DNA levels were characterized by qPCR in vaccinated and control infected fish, normalized against $D$. rerio gapdh, represented as average $+\mathrm{SD}$, and compared between groups by Student's $t$-test with unequal variance $(p<0.05)$. (D) Spearman's Rho correlation analysis between normalized M. marinum DNA levels and anti- $\alpha$-Gal IgM antibody levels. Correlation rank coefficient $(\rho)$ and $p$-value are shown. In all experiments, $n=6$ for vaccinated fish and $n=8$ for controls.

A
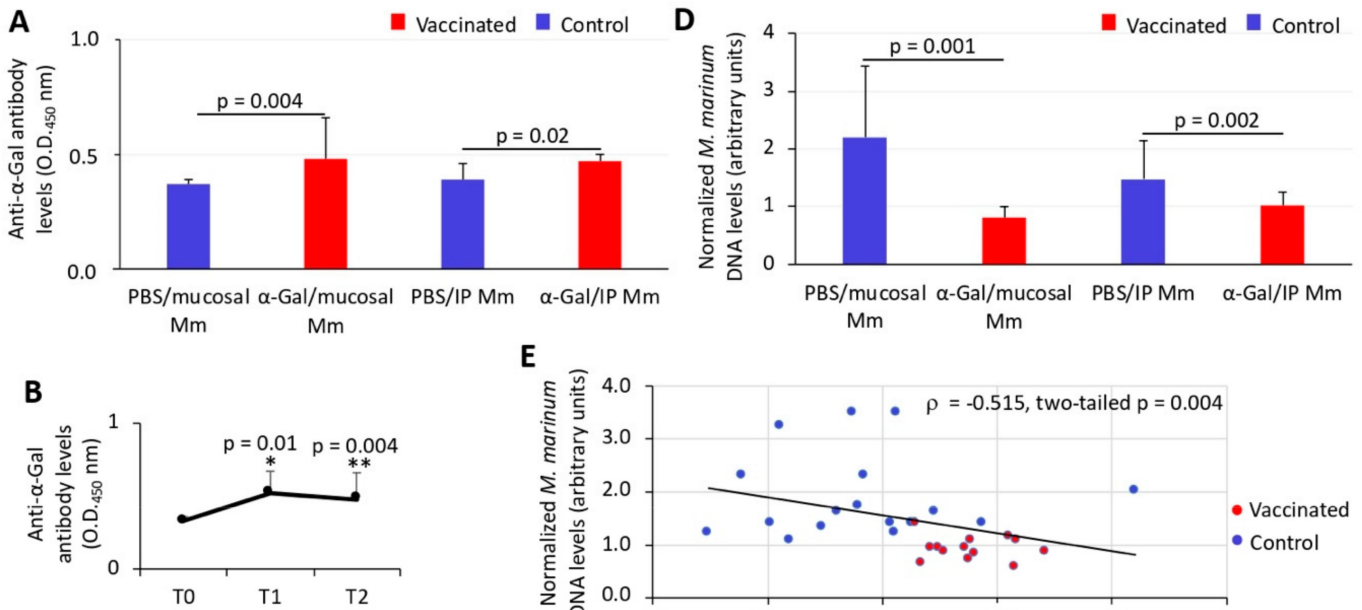

C

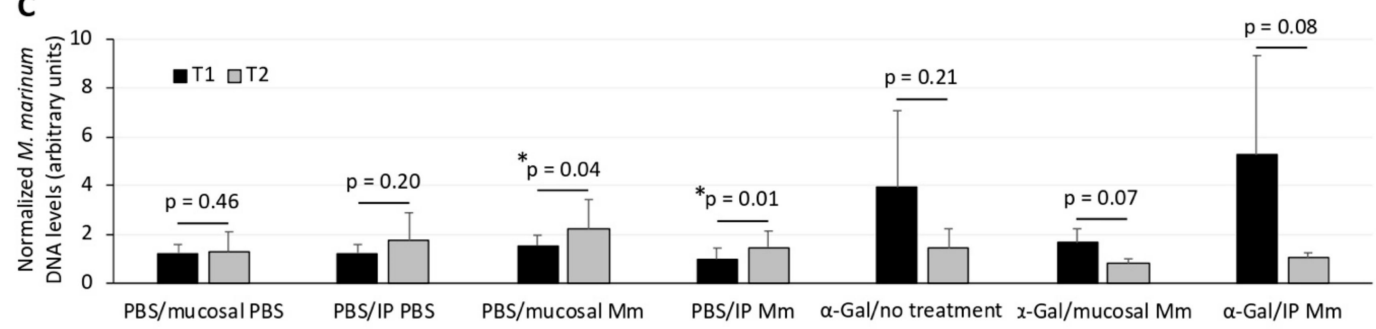

Figure 3. Experiment 2, effect of vaccination on the antibody response and mycobacterial infection levels in zebrafish. (A) The IgM antibody titers against $\alpha$-Gal were determined by ELISA at T2 in fish vaccinated with $\alpha$-Gal and PBS-treated controls infected with mucosal or IP M. marinum (Mm). Antibody titers in vaccinated and control fish were represented as the average + SD of the $\mathrm{OD}_{450 \mathrm{~nm}}$ $\left(\mathrm{OD}_{\text {antigen }}-\mathrm{OD}_{\mathrm{PBS}}\right.$ control $)$, and the mean of duplicate values were compared between vaccinated and control groups by Student's $t$-test with unequal variance $(p<0.05 ; n=6$ for fish vaccinated and IP Mm, $n=8$ for fish vaccinated and mucosal Mm, $n=7$ for PBS controls and IP Mm, and $n=10$ for PBS controls and mucosal Mm). (B) The IgM antibody titers against $\alpha$-Gal were determined by ELISA at different time points in PBS-treated uninfected fish (T0 before vaccination, $n=18$ ), vaccinated with $\alpha$-Gal and uninfected fish (T1, $n=18)$ and vaccinated with $\alpha$-Gal and untreated fish (T2, $n=8)$. Antibody titers were determined and represented as in (A) and compared by Student's $t$-test with unequal variance ( ${ }^{*} p=0.01, \mathrm{~T} 1$ vs. T0; ${ }^{* *} p=0.004, \mathrm{~T} 2$ vs. T0). (C) M. marinum DNA levels were characterized by qPCR at T1 and T2 in fish vaccinated with $\alpha$-Gal and PBS-treated controls uninfected and infected with mucosal or IP Mm, normalized against D. rerio gapdh, represented as average $+\mathrm{SD}$, and compared between $\mathrm{T} 1$ 
and T2 by Student's $t$-test with unequal variance $\left({ }^{*} p<0.05\right.$; T1: $n=7$ for PBS vaccinated uninfected fish, $n=5$ for $\alpha$-Gal vaccinated uninfected fish, $n=13$ for $\alpha$-Gal vaccinated infected fish, $n=12$ for PBS vaccinated infected fish; T2: $n=5$ for fish PBS vaccinated and IP PBS, $n=6$ for fish PBS vaccinated and mucosal PBS, $n=8$ for fish $\alpha$-Gal vaccinated and untreated, $n=6$ for fish vaccinated and IP Mm, $n=8$ for fish vaccinated and mucosal Mm, $n=7$ for controls and IP Mm, and $n=10$ for controls and mucosal Mm). (D) M. marinum DNA levels were characterized by qPCR at T2 in fish vaccinated with $\alpha$-Gal and PBS-treated controls infected with mucosal or IP Mm, normalized against $D$. rerio gapdh, represented as average $+\mathrm{SD}$, and compared between groups by Student's t-test with unequal variance $(p<0.05$; $n=6$ for fish vaccinated and IP Mm, $n=8$ for fish vaccinated and mucosal Mm, $n=7$ for controls and IP Mm, and $n=10$ for controls and mucosal Mm). (E) Spearman's Rho correlation analysis between normalized M. marinum DNA levels and anti- $\alpha$-Gal IgM antibody levels (experiment 2, $n=14$ for $\alpha$-Gal vaccinated fish and IP/mucosal infection at T2 and $n=17$ for PBS controls and IP/mucosal infection at T2). Correlation rank coefficient $(\rho)$ and $p$-value are shown.

3.3. The Tuberculous Granuloma Lesion Scores Decrease in Zebrafish Vaccinated with $\alpha$-Gal and IP Infected with Mycobacteria

None of the animals in any group presented tuberculosis-like lesions at T0 and T1 of the experiment; neither did the animals from the M. marinum uninfected groups at T2. However, tuberculous-like granulomas were observed in 100\% (IC $95 \%: 61.2 \%-100 \%$ ) of the animals from IP M. marinum-infected groups at $\mathrm{T} 2$ and in 50\% (IC $95 \%: 21.5 \%-78.4 \%$ ) and $60 \%\left(\mathrm{IC}_{95 \%}: 31.2 \%-83.1 \%\right.$ ) of the zebrafish in mucosal M. marinum-infected groups vaccinated and not vaccinated with $\alpha$-Gal, respectively. Fish vaccinated with $\alpha$-Gal and infected IP with $M$. marinum had a significantly lower mean number of tuberculous granuloma lesion score $(2 \pm 3)$ when compared to unvaccinated animals $(5 \pm 1)(p=0.03)$, while no significant differences between groups were observed in zebrafish infected by mucosal M. marinum $(2 \pm 2$ vs. $2 \pm 3 ; p>0.40)$ (Figure $4 \mathrm{~A}$ ). However, all M. marinum-infected groups presented a similar granuloma distribution of affected tissues, with the liver and gonads the organs more affected followed by intestine (Figure 4B), whereas mycobacteria were not detected in the brain, branchial arches, muscle, and skin. ZN staining confirmed the presence of mycobacteria in the cytoplasm of macrophages within granulomas of all zebrafish with tuberculous-like lesions (insets in Figure 4B(a) and (c)).

A
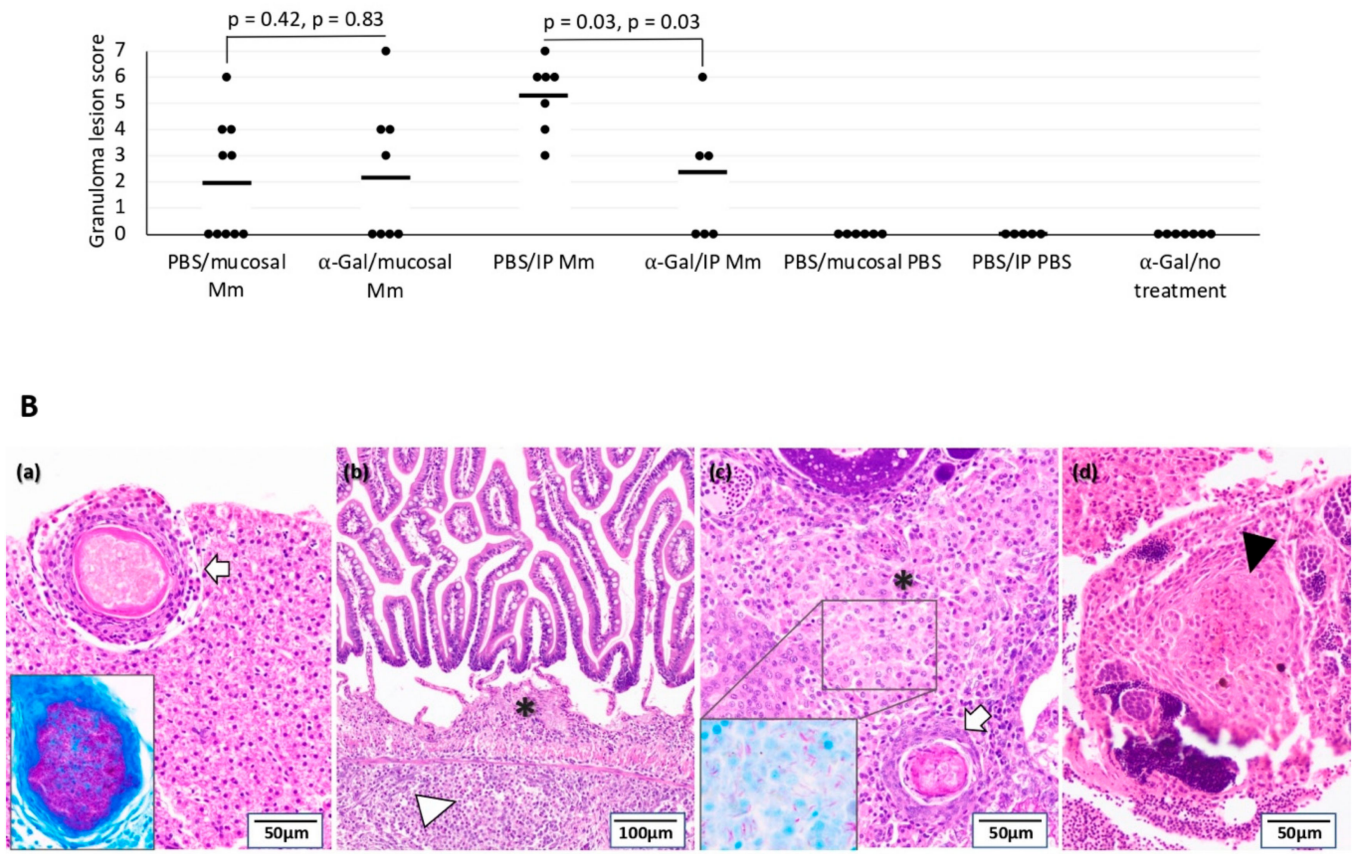

Figure 4. Effect of vaccination on tuberculous granulomas: The quantitative assessment of the 
granulomas consisted of identifying and counting the organs with granulomas per zebrafish. Pathological findings were graded by a numerical score based on the number of granulomas, the type of granulomas, and the number of regions and/or organs involved by granulomatous disease in each fish. (A) Histopathology and Ziehl-Neelsen (ZN) staining for mycobacteria were used for the quantification of granuloma lesion scores in the studied organs. The granuloma lesion scores were compared between groups by Student's $t$-test with unequal variance and by a one-way ANOVA test (https://www.socscistatistics.com/tests/anova/default2.aspx) $(p<0.05 ; n=5$ for fish PBS vaccinated and IP PBS, $n=6$ for fish PBS vaccinated and mucosal PBS, $n=7$ for fish $\alpha$-Gal vaccinated and untreated, $n=5$ for fish vaccinated and IP M. marinum, $n=8$ for fish vaccinated and mucosal M. marinum, $n=7$ for controls and IP M. marinum, and $n=9$ for controls and mucosal M. marinum). (B) Representative histopathology of zebrafish infected with M. marinum. (a) Liver tissue infected with M. marinum exhibiting tuberculosis-like mature granulomatous formation well-organized and surrounded by a capsule of connective tissue with complete central necrosis (white arrow). (b) Intestine from M. marinum-infected zebrafish presenting an early tuberculosis-like granuloma composed of epithelioid macrophages grouped loosely in lamina propia (asterisk ${ }^{*}$ ) and a diffuse epithelioid macrophages infiltrate in submucosa (white arrowhead). (c) Ovary tissue infected with M. marinum exhibiting an early tuberculosis-like granuloma composed of an epithelioid macrophage infiltrate (asterisk ${ }^{*}$ ) as well as a mature granuloma with well-defined border of macrophages and central necrosis (white arrow). (d) Testicle tissue from M. marinum-infected zebrafish showing a mature granuloma well-defined with early central necrosis (black arrowhead). A high acid-fast bacilli numbers were present in the central necrotic core of mature granulomas positive to $\mathrm{ZN}$ staining ((a), inset), while a lower bacterial number was observed residing within macrophages in early granulomas ((c), inset).

Early tuberculosis-like granulomas with epithelioid macrophage infiltrates surrounding scattered mycobacteria were predominant in M. marinum-infected zebrafish in unvaccinated groups with respect to fish vaccinated with $\alpha$-Gal, although no significant differences were observed in zebrafish infected by mucosal M. marinum (36.7\% and 50.0\% for vaccinated and unvaccinated groups, respectively; $p=0.69$ ) and IP M. marinum (38.3\% and 52.3\% for vaccinated and unvaccinated groups, respectively; $p=0.46$ ). Accordingly, a higher numbers of well-organized granulomas with partial and complete necrosis were present in not vaccinated and M. marinum-infected zebrafish but without significant differences within each group $(25.8 \%$ and $50.0 \%$ for vaccinated and not vaccinated mucosal infected groups $(p=0.37)$ and $31.7 \%$ and $42.0 \%$ for vaccinated and not vaccinated IP infected groups $(p=0.53)$ ). The acid-fast bacilli were found predominantly in necrotic areas and were in greater numbers in fully necrotic than in partially necrotic zones.

\subsection{The $\alpha$-Gal Content Varies among M. marinum Bacteria}

As previously shown [17], M. marinum has $\alpha$-Gal on its surface (Figure 5A). However, the $\alpha$-Gal content in $M$. marinum varied from negative or very low levels (37.56\% of mycobacteria) to high levels (3.25\% of mycobacteria) of $\alpha$-Gal (Figure 5B,C). These results showed that not all mycobacteria have the same $\alpha$-Gal content with possible functional implications. 
A
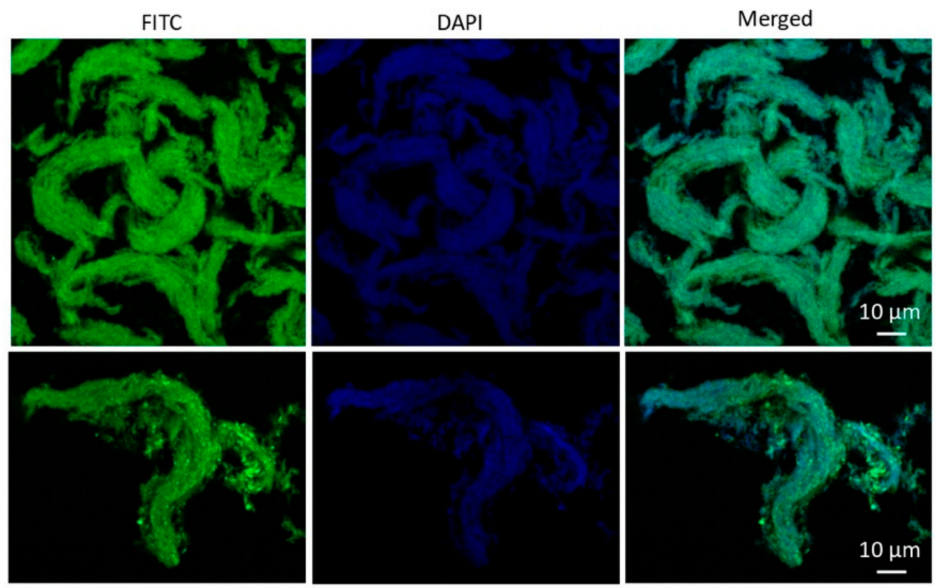

B
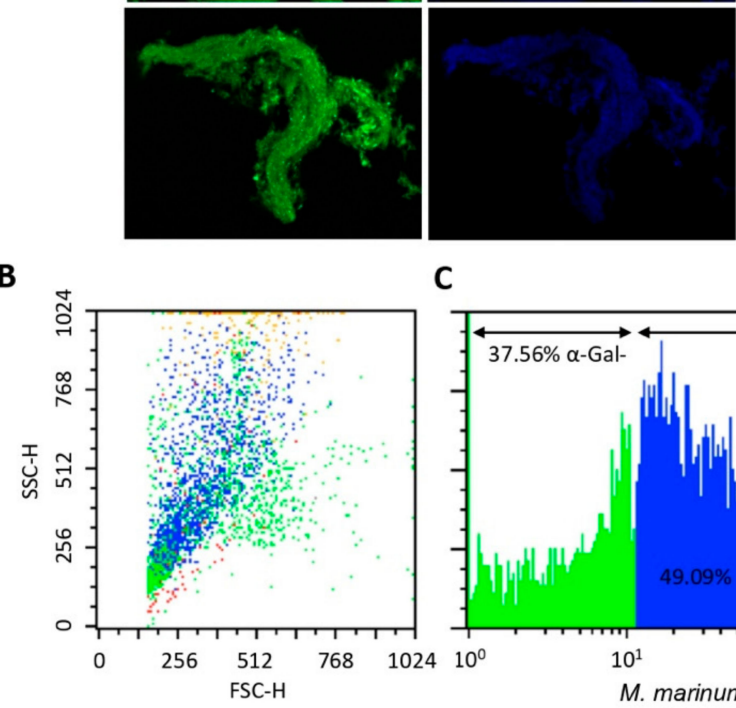

C

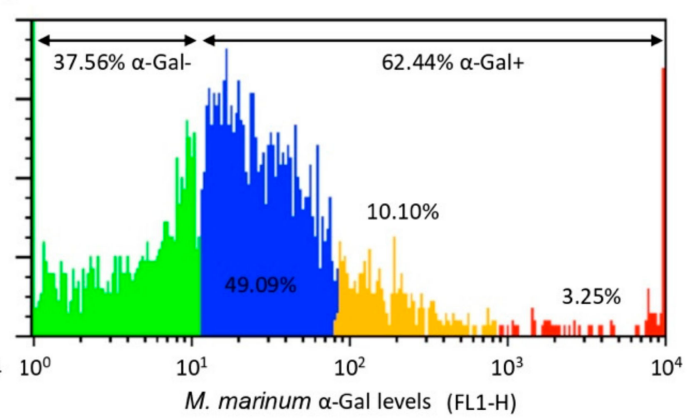

Figure 5. The $\alpha$-Gal content in M. marinum: (A) Representative immunofluorescence images of M. marinum Aronson (ATCC 927) reference strain. (B) Density plot representing M. marinum that were gated by forward (FSC-H) and side (SSC-H) scatter. (C) Mycobacteria are represented in a histogram to evaluate the relative $\alpha$-Gal levels (FL1-H). Cells were incubated with the $\alpha$-Gal epitope monoclonal antibody M86. FITC-goat anti-mouse IgM-labelled antibody was used as a secondary antibody. Samples were analyzed on a FAC-Scalibur flow cytometer equipped with CellQuest Pro software. The viable cell population was gated according to forward-scatter (FSC-H) and side-scatter (SSC-H) parameters. Aliquots of fixed and stained samples were used for immunofluorescence assays after air-drying and mounting in ProLong Antifade reagent containing DAPI. The sections were examined using a Zeiss LSM 800 laser scanning confocal microscope with oil immersion objectives (63×; bars, $10 \mu \mathrm{m})$.

\subsection{The B-Cell Maturation and TLR2/NF-kB-Mediated Immune Responses Play a Role in Mycobacterial} Infection and Protective Response to $\alpha-$ Gal in Zebrafish

The expression of selected genes previously shown to be involved in vaccine protective mechanisms and/or fish immune response to infection was characterized by qRT-PCR in experiment 1 at T2 (after vaccination and treatment/IP infection) and in experiment 2 at T1 (after vaccination and before treatment/infection) and T2 (after vaccination and treatment/IP or mucosal infection) (Figure 6A-D and Figure S1A,B). The combined effect of vaccination and treatment/infection at T2 showed that the IP infection with $M$. marinum mostly upregulated the expression of selected genes with a higher effect on fish vaccinated with the adjuvant-containing $\alpha$-Gal formulation (Figure 6A). In contrast, combined vaccination with mucosal $M$. marinum infection resulted in the downregulation or no effect of these genes (Figure 6B). In experiment 2 , the effect of vaccination with $\alpha$-Gal when compared to PBS-treated zebrafish at T1 resulted in significant $(p<0.05)$ upregulation of $I L-1 \beta, a k r 2, T L R 2, c c r 6 a$, and akr1 (Figure 6C). In zebrafish infected with IP or mucosal $M$. marinum, the effect of infection when compared to PBS-treated controls at T2 showed a significant $(p<0.05)$ downregulation in response to infection for tnf alpha and akr1 (mucosal infection) and ccr6a (IP infection) genes (Figure 6D). 
A

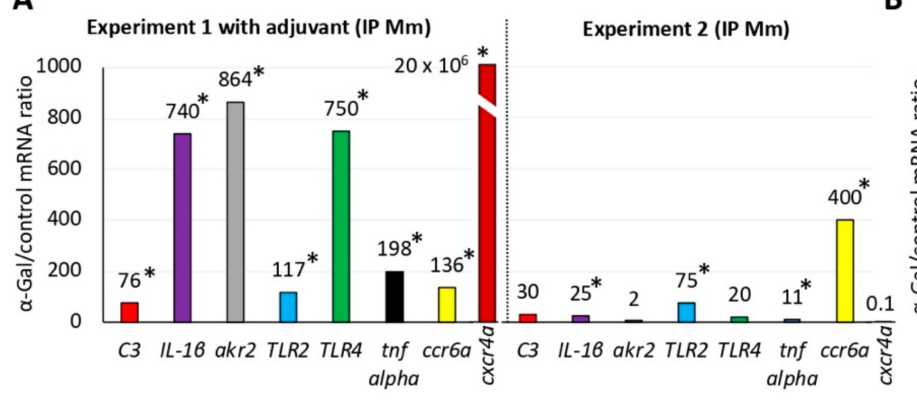

B

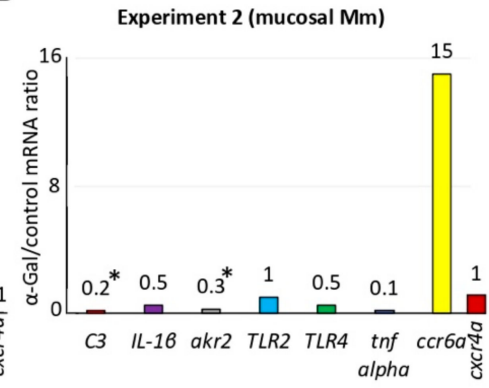

C

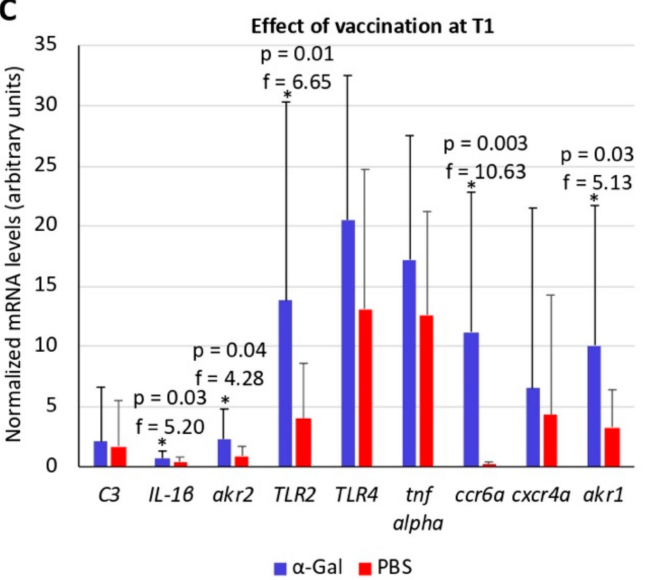

D

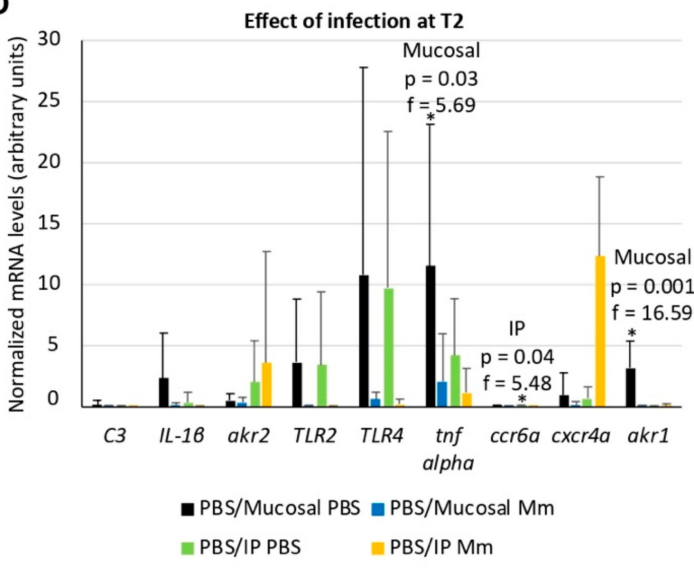

Figure 6. Effect of vaccination with $\alpha$-Gal and mycobacterial infection on the expression of zebrafish immune response genes: The expression of selected immune response genes was characterized by qRT-PCR in zebrafish in response to vaccination with $\alpha$-Gal or PBS and IP/mucosal infection with M. marinum (Mm). The mRNA levels were normalized against $D$. rerio gapdh, and normalized Ct values were compared between groups by Student's $t$-test with unequal variance $\left({ }^{*} p<0.05\right.$; Figure S1A,B) and then represented as (A) the ratio between normalized Ct values in fish $\alpha$-Gal-vaccinated and PBS or BSA control IP infected with Mm at T2 (experiment $1, n=6$ for fish $\alpha$-Gal vaccinated and $n=8$ for controls; experiment $2, n=6$ for fish $\alpha$-Gal vaccinated and $n=7$ for controls) and (B) the ratio between normalized Ct values in fish $\alpha$-Gal-vaccinated and PBS control with mucosal infection with Mm at T2 ( $n=8$ for fish $\alpha$-Gal vaccinated and $n=10$ for controls). (C) The normalized mRNA levels were compared between zebrafish vaccinated with $\alpha$-Gal $(n=18)$ and PBS $(n=19)$ to evaluate the effect of vaccination at T1 by a one-way ANOVA test (https://www.socscistatistics.com/tests/anova/default2.aspx) $\left({ }^{*} p<0.05\right)$. (D) The normalized mRNA levels were compared between zebrafish vaccinated with PBS and treated by mucosal or IP route with PBS or Mm to evaluate the effect of infection at T2 by a one-way ANOVA test (https://www.socscistatistics.com/tests/anova/default2.aspx) ${ }^{*} p<0.05 ; n=6$ PBS/mucosal PBS, $n=10 \mathrm{PBS} /$ mucosal Mm, $n=5 \mathrm{PBS} / \mathrm{IP} \mathrm{PBS}, n=7$ PBS/IP Mm).

To further evaluate the combined effect of vaccination and infection with M. marinum on zebrafish immune response genes, the mRNA levels of selected genes were compared at T1 and T2 in experiment 2 (Figures S2 and S3). The results showed that, as expected, the T1 = T2 mRNA ratio evidences no effect on immune response genes in fish vaccinated with PBS and treated with IP or mucosal PBS, thus validating the experimental design and analysis (Figures S2 and S3). The analysis of the different mRNA profiles showed that most genes had $\mathrm{T} 1=\mathrm{T} 2$ and $\mathrm{T} 1>\mathrm{T} 2$ profiles, thus suggesting no differences or a decrease in the mRNA levels after infection or no treatment in vaccinated fish (Figure S3).

After proteomics analysis, a total of 1777 proteins were identified in the zebrafish intestine (Table S1). Of them, differentially represented proteins after quantitation and comparative analysis by SWATH $(p<0.05)$ corresponded to 635 proteins (314 overrepresented and 321 underrepresented in P1 vs. P2, effect of IP infection at T2), 706 proteins (302 overrepresented and 404 underrepresented in P1 vs. P3, effect of mucosal infection at T2), 836 proteins (446 overrepresented and 390 underrepresented in 
P1 vs. P4, effect of vaccination at T1), 780 proteins (191 overrepresented and 589 underrepresented in P4 vs. P5, effect of vaccination and IP infection at T2), and 790 proteins (216 overrepresented and 574 underrepresented in P4 vs. P6, effect of vaccination and mucosal infection at T2) (Table S1). Although proteins encoded by most of the genes analyzed at the mRNA level were not identified in the proteomics analysis probably due to relatively low protein levels, these results showed an effect of the vaccination with $\alpha$-Gal and/or mycobacterial infection in more than $60 \%$ of the identified proteins, suggesting a major impact on fish intestine proteome.

Proteomics analysis was focused on the immune system process proteins with special attention to those significantly represented $(p<0.05)$ in response to infection and vaccination (Figure $7 \mathrm{~A}, \mathrm{~B}$, Figure 8 , Figures S4-S6). The effect of $M$ marinum after IP (Figure 7A and Figure S4) and mucosal infection (Figure 7B and Figure S5) showed common overrepresented (e.g., ribosomal proteins, lysine-tRNA ligase, and leukotriene A4 hydrolase LTA4H) and underrepresented (e.g., complement components including C3, annexin, and tropomyosin alpha-1) proteins in response to infection (Figure 7A,B). Other proteins such as interferon (IFN)-g-inducible lysosomal thiol reductase, cathepsin L1, and heat shock protein 9 (HSP9) were differentially represented in response to either IP or mucosal infection (Figure 7A,B). The effect of vaccination with $\alpha$-Gal evidenced the overrepresentation of proteins such as HSP9 and LTA4H, while complement components including C3, tropomyosin alpha-1, and annexin were underrepresented (Figure 8 and Figure S6). Other proteins such as ribosomal proteins were either under- or overrepresented in response to vaccination (Figure 8). Proteins such as DEAD (Asp-Glu-Ala-Asp) box polypeptide 41 (DDX41) and Rac family small GTPase 2 were underrepresented or overrepresented, respectively, in response to vaccination but did not change in response to infection (Figure 7A,B and Figure 8).

A

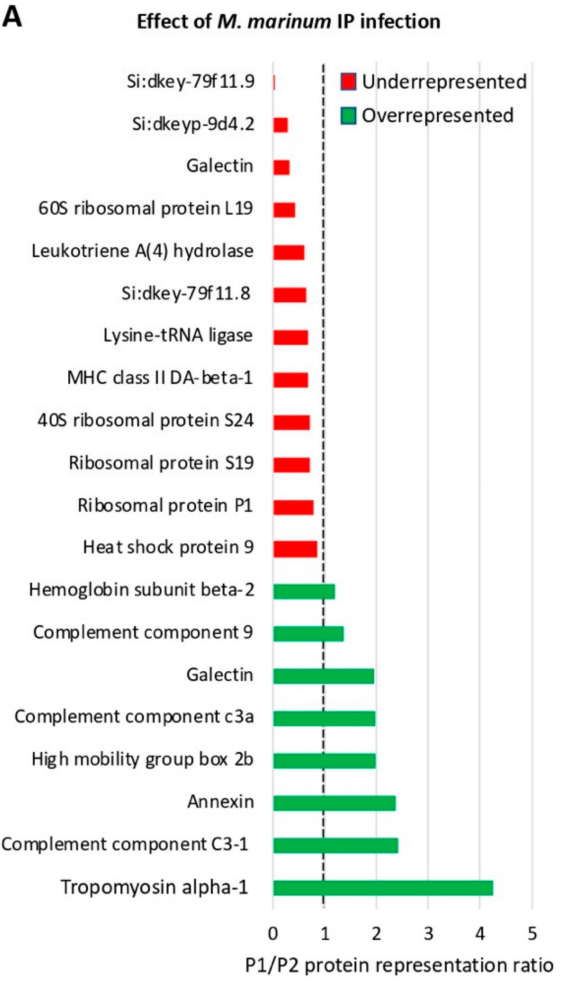

B

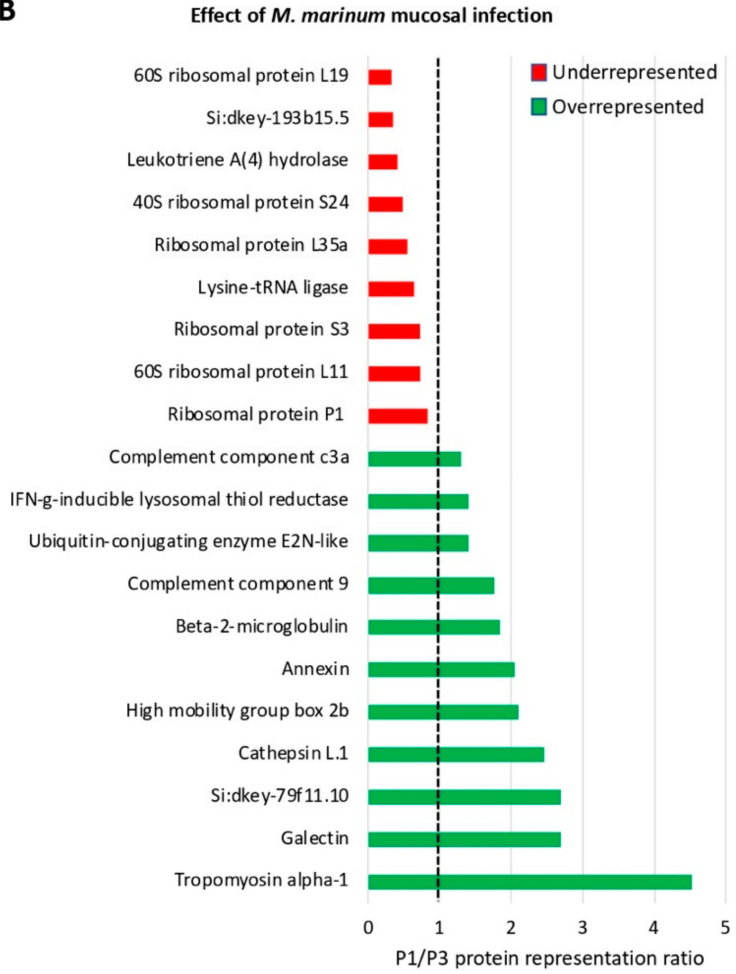

Figure 7. Proteomics analysis of immune system process proteins in response to M. marinum infection: Proteins annotated by Gene ontology (GO) using the Blast2GO software in the immune system process and significantly differentially represented between samples (Student's $t$-test; $p<0.05, n=4$ ) were included. (A) Effect of M. marinum IP infection on protein representation (P1/P2 ratio) after comparison 
between PBS-vaccinated (P1 at T1; Figure 1B) and IP-infected (P2 at T2; Figure 1B) zebrafish. (B) Effect of $M$. marinum mucosal infection on protein representation (P1/P3 ratio) after comparison between PBS-vaccinated (P1 at T1; Figure 1B) and mucosal-infected (P3 at T2; Figure 1B) zebrafish.

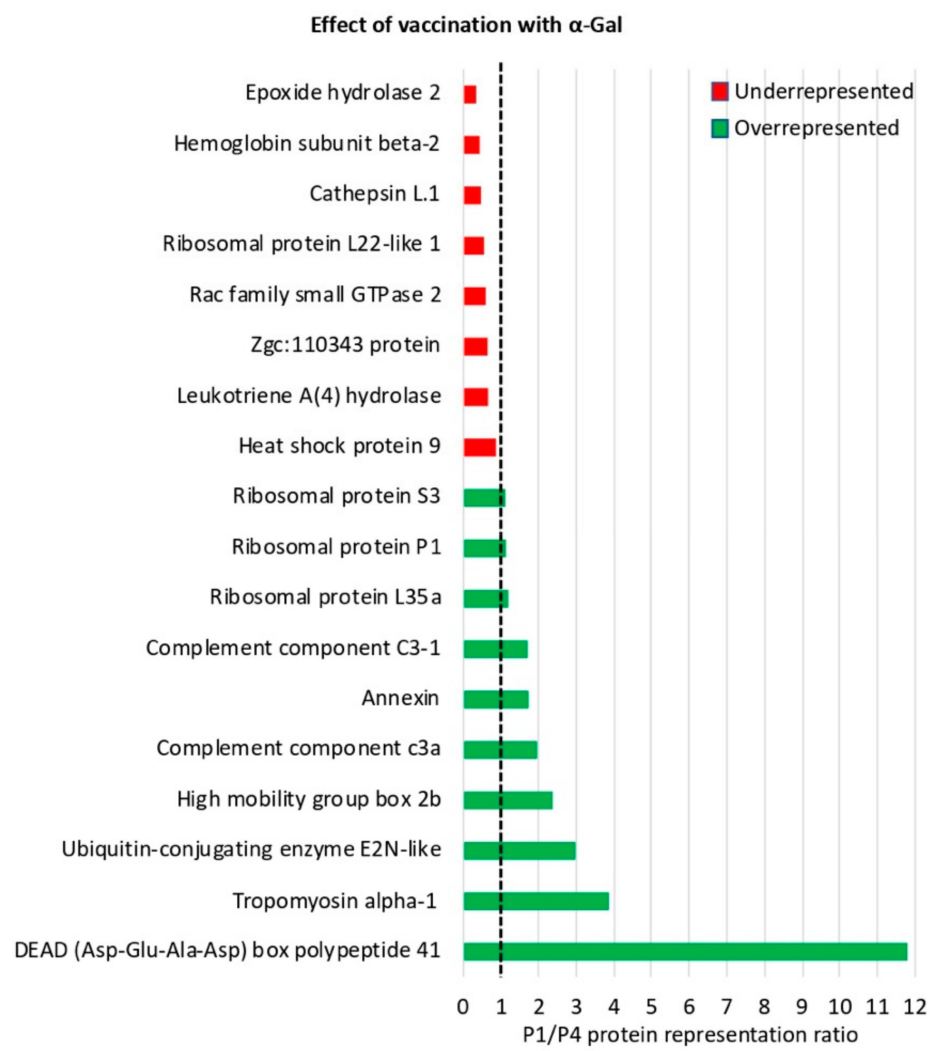

Figure 8. Proteomics analysis of immune system process proteins in response to vaccination with $\alpha$-Gal: Proteins annotated by GO using the Blast2GO software in the immune system process and significantly differentially represented between samples (Student's $t$-test; $p<0.05, n=4$ ) were included. Effect of vaccination with $\alpha$-Gal on protein representation (P1/P4 ratio) after comparison between PBS-vaccinated (P1 at T1; Figure 1B) and $\alpha$-Gal-vaccinated (P4 at T1; Figure 1B) zebrafish.

The analysis of the mRNA profiles showed that, while $C 3$ and $c x c r 4 a$ mRNA levels did not change throughout the experiment, ccr $6 a, a k r 2$, and $I L-1 \beta$ levels increased after vaccination with $\alpha$-Gal and remained unchanged after infection (Figure 9). However, the mRNA levels for TLR4, tnf alpha, akr1, and TLR2 remained unchanged or increased after vaccination but decreased after infection (Figure 9). The profiles of immune response proteins relevant for mycobacterial infection showed that LTA4H and cathepsin L1 levels increased in response to vaccination or vaccination and infection (Figure 9). However, the representation profile of DDX41 and lysine-tRNA ligase decreased and increased only in response to vaccination or infection, respectively (Figure 9). In contrast, the representation profile for complement components including C3, annexin, and tropomyosin alpha-1 decreased in response to vaccination and both IP and mucosal M. marinum infection (Figure 9). In summary, these results showed that the mRNA/protein levels of immune response markers involved in B-cell maturation (e.g., ccr6a) and TLR2/NF-kB-mediated response (e.g., TLR2, akr1, akr2, tnf alpha/IL-1, LTA4H, and cathepsin L1) are downregulated/underrepresented, are overrepresented, or do no change in response to mycobacterial infection while upregulated/overrepresented in response to vaccination with $\alpha$-Gal. The C3 protein levels showed underrepresentation in response to both vaccination and mycobacterial infection, a result that correlated with no effect on gene regulation (Figure 9). 


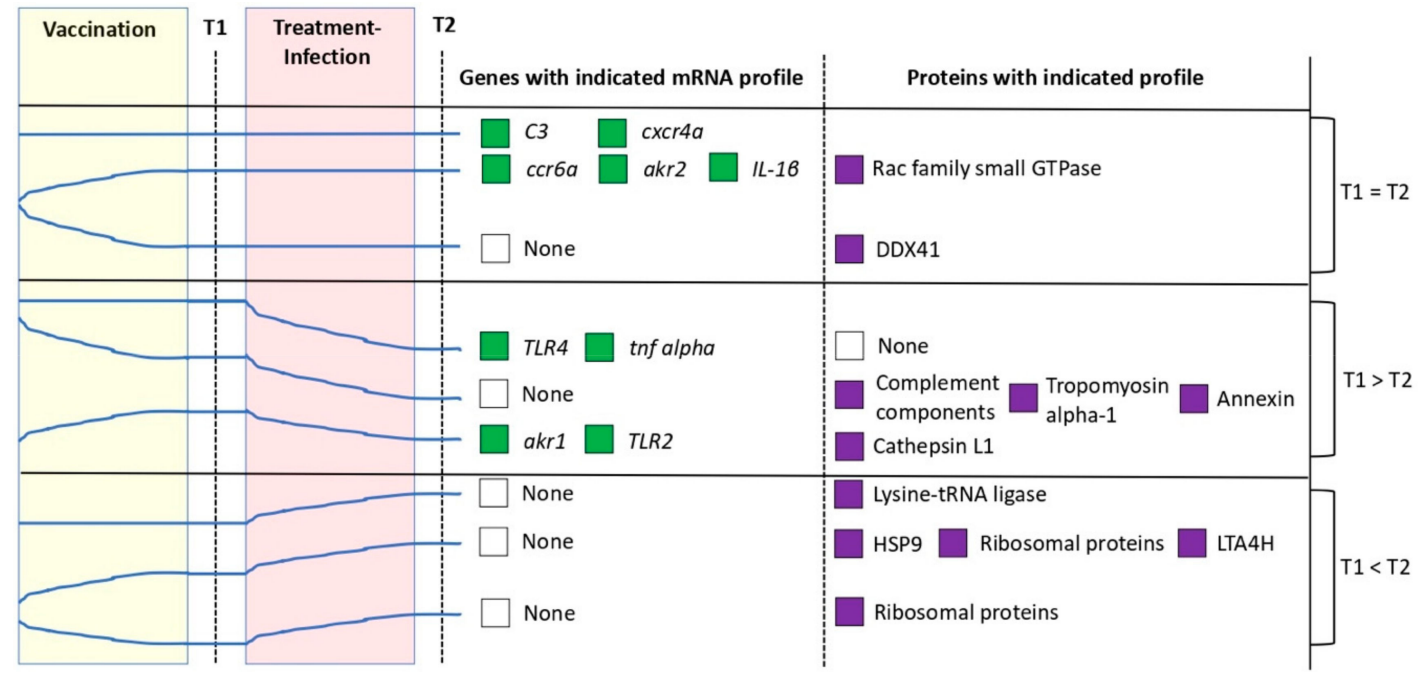

Figure 9. Summary mRNA and protein profiles of selected immune markers in response to vaccination and infection: The mRNA and protein profiles of selected immune response genes in response to vaccination at $\mathrm{T} 1$ and to treatment-infection at $\mathrm{T} 2$ are shown by tendency lines, which were associated to the corresponding genes or proteins. The results were compiled from qRT-PCR (Figure 6 and Figure S3) and proteomics (Figure 7A,B and Figure 8) analyses for experiment 2 at T1 and T2 (Figure 1B). Only statistically significant differences $(p<0.05)$ in mRNA and protein levels were considered. The results showed that the mRNA/protein levels of immune response markers involved in B-cell maturation (e.g., ccr6a), macrophage response (e.g., annexin), and TLR2/NF-kB-mediated response (e.g., TLR2, akr1, akr2, tnf alpha/IL-1 $\beta$, DDX41, and Lysine-tRNA ligase) are downregulated by mycobacterial infection and upregulated in response to vaccination with $\alpha$-Gal.

\section{Discussion}

The possibility of using the antibody-mediated immune response against $\alpha$-Gal for the control of infectious diseases caused by pathogens with this modification on their surface in hosts such as humans, birds, and fishes that do not have the capacity to synthesize $\alpha$-Gal was initially suggested by results in the malaria mouse model [15]. Then, results in leishmaniasis and Chagas disease further supported this possibility [18-20], leading to proposing the possibility of development of a single-antigen pan-vaccine for the control of major infectious diseases worldwide $[11,16,17,30]$. Pathogens causing infectious diseases with high incidence worldwide and with $\alpha$-Gal modifications include Plasmodium, Mycobacterium, Leishmania, Trypanosoma, Anaplasma, Borrelia, and Aspergillus species and viruses such as human immunodeficiency virus (HIV), measles virus, vaccinia virus, paramyxovirus, vesicular stomatitis virus, Sindbis virus, and retroviruses [6,9,14,15,17-21].

The mechanisms behind the possibility of using $\alpha$-Gal for developing a single-antigen pan-vaccine for the control of infectious diseases caused by pathogens with this modification on their surface include pathogen opsonization by anti- $\alpha$-Gal IgM/IgG-type antibodies and boosting the non-pathogen-specific protective immune mechanisms [10,14-21]. The immunization with $\alpha$-Gal will increase the levels of the natural anti- $\alpha$-Gal IgM/IgG-type antibodies produced in response to gut microbiota [15] and do not cause an increase in the IgE-type allergic response to tick saliva, which are involved in triggering the AGS $[1-12,15,40]$. Therefore, in principle, the $\alpha$-Gal-based vaccines could be applied to all hosts that do not produce $\alpha-G a l$, but the immune response could be affected by different factors including the ABO blood groups [17].

In this study, we provided additional support for this proposal by characterizing the protective effect of the anti- $\alpha$-Gal immune response for the control of tuberculosis caused by Mycobacterium spp. using the zebrafish model. The zebrafish model of tuberculosis has been used in our laboratory for the characterization of the protective response elicited after vaccination with heat inactivated $M$. bovis (IV) $[27,28]$. In these experiments, we showed a reduction of mycobacteriosis in vaccinated 
fish and suggested that the innate immune response mediated by the C3 pathway activated through TLR-AKR2-IL-1 $\beta$ and other proinflammatory cytokines acted as the protective mechanism against infection. Herein, the results showed some similarities and differences in the immune mechanisms activated by vaccination with IV and $\alpha$-Gal.

The results suggested that $M$. marinum affects the zebrafish immunity by downregulating the expression of immune response genes with a stronger effect after mucosal infection that reproduces better the natural infection conditions. However, alternative innate immune mechanisms may be activated in response to mycobacterial infection [41]. Similar to vaccination with IV [27,28], the upregulation of proinflammatory cytokines through the TLR/NF-kB-AKR pathway was shown to be an $\alpha$-Gal-induced putative protective mechanism to mycobacterial infection [42-44] (Figure 10). The use of adjuvant-containing $\alpha$-Gal formulation showed higher levels of immune response genes in response to vaccination and infection when compared to $\alpha-G a l$ alone, thus suggesting that adjuvants may be considered to improve vaccine efficacy. However, the C3 pathway proposed to be involved in protective response to IV was not activated in $\alpha$-Gal-vaccinated zebrafish. These results suggested that mycobacterial $\alpha$-Gal may be like glycolipids that antagonize TLR2-mediated response (Figure 10). Cell envelope glycolipids and particularly sulfoglycolipids has been shown to inhibit NF- $\kappa B / A K R$ activation and subsequent cytokine production by acting as competitive antagonists of TLR2, thereby inhibiting the recognition of mycobacteria by this receptor [45].

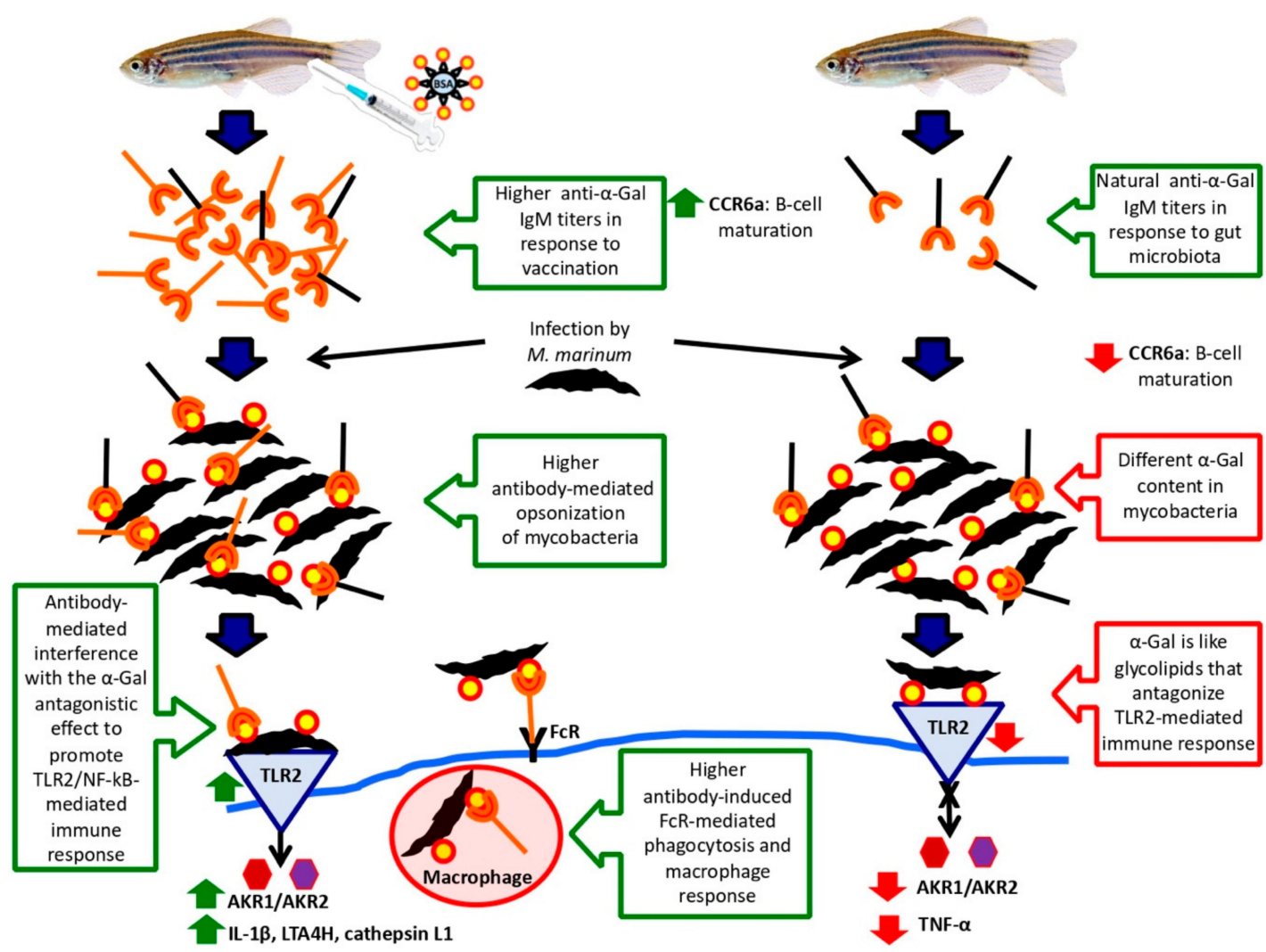

Figure 10. Immune mechanisms involved in mycobacterial infection and protective response to $\alpha$-Gal in zebrafish: Zebrafish naturally produce anti- $\alpha$-Gal IgM antibodies in response to gut microbiota with $\alpha$-Gal modifications. However, vaccination with $\alpha$-Gal results in higher anti- $\alpha$-Gal IgM antibody levels. Additionally, while infection with M. marinum results in ccr6a downregulation, vaccination with $\alpha$-Gal upregulates this gene to promote B-cell maturation and antibody production. Differences in $\alpha$-Gal content between different mycobacteria may be an adaptive mechanism to prevent the anti- $\alpha$-Gal IgM-mediated bacterial opsonization, which nevertheless will be more effective in vaccinated zebrafish. 
This mechanism will also interfere with the $\alpha$-Gal antagonistic effect to TLR2-mediated immune response. In this way, while mycobacterial infection interferes with the TLR2/NF-kB pathway, the induction of the TLR2/NF-kB pathway in response to vaccination will promote the immunity and the FcR-mediated phagocytosis and macrophage response in vaccinated zebrafish to control mycobacteriosis.

The previously shown role of antibodies against mycobacterial surface-exposed antigens in the control of tuberculosis [46] was also supported by results of our study. Zebrafish are $\alpha$-Gal negative and have natural anti- $\alpha-\mathrm{Gal}$ antibodies in response to gut microbiota [29]. Mycobacteria contain $\alpha$-Gal on their surface, and therefore, antibodies against this antigen can opsonize M. marinum and promote $\mathrm{Fc}_{\mathrm{c}}$-receptor $(\mathrm{FcR})$-mediated phagocytosis and macrophage response with a higher effect in vaccinated zebrafish with higher anti- $\alpha$-Gal antibody levels (Figure 10). The expression of the gene coding for the CCR6a beta chemokine receptor, which has been implicated in B-lineage maturation and antigen-driven B-cell differentiation and humoral immunity [47], was downregulated in response to infection but upregulated in vaccinated zebrafish, thus promoting the production of anti- $\alpha-\mathrm{Gal}$ antibodies (Figure 10). Furthermore, tnf alpha was downregulated by M. marinum infection but not after vaccination with $\alpha$-Gal, thus supporting a role for this cytokine in augmenting cell-mediated immunity in vaccinated zebrafish [46] (Figure 10). Antibody-mediated macrophage activation increases TNF- $\alpha$ secretion, which plays a major role in macrophage recruitment to the infection site during the initial and long-term control of tuberculosis [48]. Remarkably, the results showed that not all mycobacteria have the same $\alpha$-Gal content, which may constitute an adaptation to escape from the anti- $\alpha$-Gal antibody protective response in infected hosts. Nevertheless, higher anti- $\alpha-G a l$ antibody levels in vaccinated fish may mediate the interference with the $\alpha$-Gal antagonistic effect to promote TLR2-mediated immune response (Figure 10).

Despite the finding that fish vaccinated with $\alpha$-Gal showed a decrease in M. marinum infection levels, only animals infected with IP M. marinum had a significantly lower number of tuberculous granuloma lesions when compared to unvaccinated animals, and all M. marinum-infected groups showed a similar granuloma distribution of affected tissues. The chemokine receptor CXCR4 promotes granuloma formation and induction of angiogenesis by M. marinum [49]. Furthermore, cxcr4 mRNA levels increase in patients with tuberculosis whereas amelioration of disease reduces receptor expression in vivo [50]. The C3 cleavage fragments modulate CXCR4-mediated response [51,52]; TNF- $\alpha$, which stimulates the production of C3 [53], is also important in granuloma formation; and its neutralization results in the loss of granuloma structure [47]. In zebrafish, cxcr4 mRNA levels did not change in response to vaccination with $\alpha$-Gal and infection with M. marinum, and tnf alpha was downregulated in response to infection (Figure 6A-D and Figure 7). These results supported that vaccination with $\alpha$-Gal decreases mycobacterial infection by mechanisms not mediated by the $\mathrm{C} 3$ pathway that has been proposed to be involved in protective response to vaccination with IV $[27,28,36,54]$.

\section{Conclusions}

Vaccination with $\alpha$-Gal protected against mycobacteriosis in the zebrafish model of tuberculosis. The results provided evidence that the protective mechanisms in response to vaccination with $\alpha$-Gal include B-cell maturation, antibody-mediated opsonization of mycobacteria, FcR-mediated phagocytosis, macrophage response, interference with the $\alpha$-Gal antagonistic effect of the TLR2/NF-kB-mediated immune response, and upregulation of pro-inflammatory cytokines. These mechanisms result in the decrease of mycobacteria levels through the activation of the humoral and cellular immune responses. These results provided additional evidence supporting the role of the $\alpha$-Gal-induced immune response in the control of infections caused by pathogens with this modification on their surface and the possibility of using this approach for the control of multiple infectious diseases. The fact that vaccination with IV and $\alpha$-Gal activate different immune protective mechanisms suggested that it may be possible to combine these antigens in future experiments to increase vaccine efficacy against mycobacterial infection. 
Supplementary Materials: The following are available online at http://www.mdpi.com/2076-393X/8/2/195/s1, Figure S1: Effect of zebrafish vaccination with $\alpha$-Gal and mycobacterial infection on the expression of immune response genes in experiments 1 (Figure S1A) and 2 (Figure S1B), Figure S2: Effect of different treatments/vaccination and mycobacterial infection on the T1 to T2 mRNA ratio of immune response genes, Figure S3: mRNA profile of immune response genes in response to different treatments/vaccination and mycobacterial infection, Figure S4: Differentially represented proteins in response to mycobacterial IP infection at T2, Figure S5: Differentially represented proteins in response to mycobacterial mucosal infection at T2, Figure S6: Differentially represented proteins in response to vaccination with $\alpha-$ Gal at T1, Table S1: Proteomics results.

Author Contributions: Conceptualization, J.d.1.F., M.V., A.C.-C., and C.G.; methodology, J.d.l.F. and M.V.; validation, I.P., M.C., and P.A.; formal analysis, J.d.1.F.; investigation, I.P., M.C., M.V., M.A.R., and P.A.; data curation, I.P., and M.V.; writing—original draft preparation, J.d.l.F.; writing—review and editing, J.d.l.F., M.V., A.C.-C., and C.G.; visualization, J.d.l.F. and M.V.; supervision, J.d.1.F. and M.V.; project administration, J.d.1.F., M.V., and C.G.; funding acquisition, J.d.l.F., M.V., and C.G.; All authors have read and agreed to the published version of the manuscript.

Funding: This study was supported by the Consejería de Educación, Cultura y Deportes, JCCM, Spain, projects CCM17-PIC-036 (SBPLY/17/180501/000185) and SBPLY/19/180501/000174. M.V. was supported by the University of Castilla La Mancha, UCLM, Spain, and the Fondo Europeo de Desarrollo Regional, FEDER, EU.

Acknowledgments: We thank Juan Galcerán Sáez (IN-CSIC-UMH, Spain) for providing zebrafish and Almudena González García and David Fernández (IREC, Spain) for technical assistance with the fish experimental facility.

Conflicts of Interest: The authors declare no conflicts of interest.

\section{References}

1. Van Nunen:, S.; O'Connor, K.S.; Clarke, L.R.; Boyle, R.X.; Fernando, S.L. The association between Ixodes holocyclus tick bite reactions and red meat allergy. Intern. Med. J. 2007, 39, A132.

2. Commins, S.P.; Satinover, S.M.; Hosen, J.; Mozena, J.; Borish, L.; Lewis, B.D.; Woodfolk, J.A.; Platts-Mills, T.A. Delayed anaphylaxis, angioedema, or urticaria after consumption of red meat in patients with IgE antibodies specific for galactose-alpha-1,3-galactose. J. Allergy Clin. Immunol. 2009, 123, 426-433. [CrossRef] [PubMed]

3. Steinke, J.W.; Platts-Mills, T.A.; Commins, S.P. The alpha-gal story: Lessons learned from connecting the dots. J. Allergy Clin. Immunol. 2015, 135, 589-596. [CrossRef] [PubMed]

4. Platts-Mills, T.A.; Schuyler, A.J.; Tripathi, A.; Commins, S.P. Anaphylaxis to the carbohydrate side chain alpha-gal. Immunol. Allergy Clin. North. Am. 2015, 35, 247-260. [CrossRef] [PubMed]

5. Mateos-Hernández, L.; Villar, M.; Moral, A.; Rodríguez, C.G.; Arias, T.A.; de la Osa, V.; Brito, F.F.; Fernández de Mera, I.G.; Alberdi, P.; Ruiz-Fons, F.; et al. Tick-host conflict: Immunoglobulin E antibodies to tick proteins in patients with anaphylaxis to tick bite. Oncotarget 2017, 8, 20630-20644. [CrossRef] [PubMed]

6. Galili, U. Evolution in primates by "Catastrophic-selection" interplay between enveloped virus epidemics, mutated genes of enzymes synthesizing carbohydrate antigens, and natural anticarbohydrate antibodies. Am. J. Phys. Anthropol. 2019, 168, 352-363. [CrossRef]

7. Hilger, C.; Fischer, J.; Wölbing, F.; Biedermann, T. Role and mechanism of galactose-alpha-1,3-galactose in the elicitation of delayed anaphylactic reactions to red meat. Curr. Allergy Asthma Rep. 2019, 19, 3. [CrossRef]

8. Cabezas-Cruz, A.; Valdés, J.; de la Fuente, J. Cancer research meets tick vectors for infectious diseases. Lancet Infect. Dis. 2014, 10, 916-917. [CrossRef]

9. Cabezas-Cruz, A.; Hodžić, A.; Román-Carrasco, P.; Mateos-Hernández, L.; Duscher, G.G.; Sinha, D.K.; Hemmer, W.; Swoboda, I.; Estrada-Peña, A.; de la Fuente, J. Environmental and molecular drivers of the $\alpha$-Gal syndrome. Front. Immunol. 2019, 10, 1210. [CrossRef]

10. De la Fuente, J.; Pacheco, I.; Villar, M.; Cabezas-Cruz, A. The alpha-Gal syndrome: New insights into the tick-host conflict and cooperation. Parasit. Vectors 2019, 12, 154. [CrossRef]

11. Platts-Mills, T.A.E.; Commins, S.P.; Biedermann, T.; van Hage, M.; Levin, M.; Beck, L.A.; Diuk-Wasser, M.; Jappe, U.; Apostolovic, D.; Minnicozzi, M.; et al. On the cause and consequences of IgE to galactose- $\alpha$-1,3-galactose: A report from the National Institute of Allergy and Infectious Disease workshop on understanding IgE-mediated mammalian meat allergy. J. Allergy Clin. Immunol. 2020, S0091-6749, 30190-30191. [CrossRef] [PubMed]

12. Iweala, O.I.; Choudhary, S.K.; Addison, C.T.; Batty, C.J.; Kapita, C.M.; Amelio, C.; Schuyler, A.J.; Deng, S.; Bachelder, E.M.; Ainslie, K.M.; et al. Glycolipid-mediated basophil activation in alpha-gal allergy. J. Allergy Clin. Immunol. 2020, S0091-6749, 30258-30260. [CrossRef] [PubMed] 
13. De la Fuente, J.; Villar, M.; Cabezas-Cruz, A.; Estrada-Peña, A.; Ayllón, N.; Alberdi, P. Tick-host-pathogen interactions: Conflict and cooperation. PLoS Pathog. 2016, 12, e1005488. [CrossRef]

14. Hodžić, A.; Mateos-Hernández, L.; Frealle, E.; Román-Carrasco, P.; Alberdi, P.; Pichavant, M.; Risco-Castillo, V.; Le Roux, D.; Vicogne, J.; Hemmer, W.; et al. Infection with Toxocara canis inhibits the production of IgE antibodies to $\alpha$-Gal in humans: Towards a conceptual framework of the hygiene hypothesis? Vaccines 2020, 8, 167. [CrossRef]

15. Yilmaz, B.; Portugal, S.; Tran, T.M.; Gozzelino, R.; Ramos, S.; Gomes, J.; Regalado, A.; Cowan, P.J.; d'A Apice, A.J.; Chong, A.S.; et al. Gut microbiota elicits a protective immune response against malaria transmission. Cell 2014, 159, 1277-1289. [CrossRef]

16. Cabezas Cruz, A.; Valdés, J.J.; de la Fuente, J. Control of vector-borne infectious diseases by human immunity against $\alpha$-Gal. Expert Rev. Vaccines 2016, 15, 953-955. [CrossRef]

17. Cabezas-Cruz, A.; Mateos-Hernández, L.; Alberdi, P.; Villar, M.; Riveau, G.; Hermann, E.; Schacht, A.; Khalife, J.; Correia-Neves, M.; Gortazar, C.; et al. Effect of blood type on anti- $\alpha$-Gal immunity and the incidence of infectious diseases. Exp. Mol. Med. 2017, 49, e301. [CrossRef]

18. Iniguez, E.; Schocker, N.S.; Subramaniam, K.; Portillo, S.; Montoya, A.L.; Al-Salem, W.S.; Torres, C.L.; Rodriguez, F.; Moreira, O.C.; Acosta-Serrano, A.; et al. An $\alpha$-Gal-containing neoglycoprotein-based vaccine partially protects against murine cutaneous leishmaniasis caused by Leishmania major. PLoS Negl. Trop. Dis. 2017, 11, e0006039. [CrossRef]

19. Moura, A.P.V.; Santos, L.C.B.; Brito, C.R.N.; Valencia, E.; Junqueira, C.; Filho, A.A.P.; Sant'Anna, M.R.V.; Gontijo, N.F.; Bartholomeu, D.C.; Fujiwara, R.T.; et al. Virus-like particle display of the $\alpha$-Gal carbohydrate for vaccination against Leishmania infection. ACS Cent. Sci. 2017, 3, 1026-1031. [CrossRef]

20. Portillo, S.; Zepeda, B.G.; Iniguez, E.; Olivas, J.J.; Karimi, N.H.; Moreira, O.C.; Marques, A.F.; Michael, K.; Maldonado, R.A.; Almeida, I.C. A prophylactic $\alpha$-Gal-based glycovaccine effectively protects against murine acute Chagas disease. NPJ Vaccines 2019, 4, 13. [CrossRef]

21. Hodžić, A.; Mateos-Hernández, L.; Leschnik, M.; Alberdi, P.; Rego, R.O.M.; Contreras, M.; Villar, M.; de la Fuente, J.; Cabezas-Cruz, A.; Duscher, G.G. Tick bites induce anti- $\alpha$-Gal antibodies in dogs. Vaccines 2019, 7, 114. [CrossRef] [PubMed]

22. Yan, L.M.; Lau, S.P.N.; Poh, C.M.; Chan, V.S.F.; Chan, M.C.W.; Peiris, M.; Poon, L.L.M. Heterosubtypic protection induced by a live attenuated Influenza virus vaccine expressing galactose- $\alpha-1,3$-galactose epitopes in infected cells. mBio 2020, 11, e00027-20. [CrossRef] [PubMed]

23. Salazar-Austin, N.; Dowdy, D.W.; Chaisson, R.E.; Golub, J.E. 70 years of TB prevention: Efficacy, effectiveness, toxicity, durability and duration. Am. J. Epidemiol. 2019, 188, 2078-2085. [PubMed]

24. Ramakrishnan, L. Looking within the zebrafish to understand the tuberculous granuloma. Adv. Exp. Med. Bio. 2013, 783, 251-266.

25. Cronan, M.R.; Tobin, D.M. Fit for consumption: Zebrafish as a model for tuberculosis. Dis. Mod. Mec. 2014, 7, 777-784. [CrossRef]

26. Van Leeuwen, L.M.; van der Sar, A.M.; Bitter, W. Animal models of tuberculosis: Zebrafish. Cold Spring Harb. Perspect. Med. 2015, 5, a018580. [CrossRef]

27. López, V.; Risalde, M.A.; Contreras, M.; Mateos-Hernández, L.; Vicente, J.; Gortázar, C.; de la Fuente, J. Heat-inactivated Mycobacterium bovis protects zebrafish against mycobacteriosis. J. Fish Dis. 2018, 41, 1515-1528. [CrossRef]

28. Risalde, M.A.; López, V.; Contreras, M.; Mateos-Hernández, L.; Gortázar, C.; de la Fuente, J. Control of mycobacteriosis in zebrafish (Danio rerio) mucosally vaccinated with heat-inactivated Mycobacterium bovis. Vaccine 2018, 36, 4447-4453. [CrossRef]

29. Contreras, M.; Pacheco, I.; Alberdi, P.; Díaz-Sánchez, S.; Artigas-Jerónimo, S.; Mateos-Hernández, L.; Villar, M.; Cabezas-Cruz, A.; de la Fuente, J. Allergic reactions and immunity in response to tick salivary biogenic substances and red meat consumption in the zebrafish model. Front. Cell. Infect. Microbiol. 2020, 10, 78. [CrossRef]

30. Cabezas-Cruz, A.; de la Fuente, J. Immunity to $\alpha$-Gal: Towards a single-antigen pan-vaccine to control major infectious diseases. ACS Cent. Sci. 2017, 3, 1140-1142. [CrossRef]

31. Aubry, A.; Mougari, F.; Reibel, F.; Cambau, E. Mycobacterium marinum. Microbiol. Spectr. 2017, 5. [CrossRef] 
32. Contreras, M.; Alberdi, P.; Fernández De Mera, I.G.; Krull, C.; Nijhof, A.; Villar, M.; de la Fuente, J. Vaccinomics approach to the identification of candidate protective antigens for the control of tick vector infestations and Anaplasma phagocytophilum infection. Front. Cell. Infect. Microbiol. 2017, 7, 360. [CrossRef]

33. Cosma, C.L.; Swaim, L.E.; Volkman, H.; Ramakrishnan, L.; Davis, J.M. Zebrafish and frog models of Mycobacterium marinum infection. Curr. Protoc. Microbiol. 2006, 10, 10B.2.

34. Ririe, K.M.; Rasmussen, R.P.; Wittwer, C.T. Product differentiation by analysis of DNA melting curves during the polymerase chain reaction. Anal. Biochem. 1997, 245, 154-160. [CrossRef]

35. Livak, K.J.; Schmittgen, T.D. Analysis of relative gene expression data using real-time quantitative PCR and the 2(-Delta Delta C(T)) Method. Methods 2001, 25, 402-408. [CrossRef]

36. Beltrán-Beck, B.; de la Fuente, J.; Garrido, J.M.; Aranaz, A.; Sevilla, I.; Villar, M.; Boadella, M.; Galindo, R.C.; Pérez de la Lastra, J.M.; Moreno-Cid, J.A.; et al. Oral vaccination with heat inactivated Mycobacterium bovis activates the complement system to protect against tuberculosis. PLoS ONE 2014, 9, e98048. [CrossRef]

37. Benard, E.L.; Rougeot, J.; Racz, P.I.; Spaink, H.P.; Meijer, A.H. Transcriptomic approaches in the zebrafish model for tuberculosis-insights into host- and pathogen-specific determinants of the innate immune response. Adv. Genet. 2016, 95, 217-251.

38. Gillet, L.C.; Navarro, P.; Tate, S.; Röst, H.; Selevsek, N.; Reiter, L.; Bonner, R.; Aebersold, R. Targeted data extraction of the MS/MS spectra generated by data-independent acquisition: A new concept for consistent and accurate proteome analysis. Mol. Cell. Proteom. 2012, 11, O111.016717. [CrossRef]

39. Shilov, I.V.; Seymour, S.L.; Patel, A.A.; Loboda, A.; Tang, W.H.; Keating, S.P.; Hunter, C.L.; Nuwaysir, L.M.; Schaeffer, D.A. The paragon algorithm, a next generation search engine that uses sequence temperature values and feature probabilities to identify peptides from tandem mass spectra. Mol. Cell. Proteom. 2007, 6, 1638-1655. [CrossRef]

40. Villar, M.; Pacheco, I.; Merino, O.; Contreras, M.; Mateos-Hernández, L.; Prado, E.; Barros-Picanco, D.K.; Francisco Lima-Barbero, J.; Artigas-Jerónimo, S.; Alberdi, P.; et al. Tick and host derived compounds modulate the biochemical properties of the cement complex substance. Biomolecules 2020, 10, 555. [CrossRef]

41. Lim, H.X.; Jung, H.J.; Lee, A.; Park, S.H.; Han, B.W.; Cho, D.; Kim, T.S. Lysyl-transfer RNA synthetase induces the maturation of dendritic cells through MAPK and NF- $\mathrm{kB}$ pathways, strongly contributing to enhanced Th1 cell responses. J. Immunol. 2018, 201, 2832-2841. [CrossRef]

42. Maji, A.; Misra, R.; Kumar Mondal, A.; Kumar, D.; Bajaj, D.; Singhal, A.; Arora, G.; Bhaduri, A.; Sajid, A.; Bhatia, S.; et al. Expression profiling of lymph nodes in tuberculosis patients reveal inflammatory milieu at site of infection. Sci. Rep. 2015, 5, 15214. [CrossRef]

43. Haeggström, J.Z.; Tholander, F.; Wetterholm, A. Structure and catalytic mechanisms of leukotriene A4 hydrolase. Prostaglandins Other Lipid Mediat. 2007, 83, 198-202. [CrossRef]

44. Rodriguez, A.R.; Yu, J.J.; Guentzel, M.N.; Navara, C.S.; Klose, K.E.; Forsthuber, T.G.; Chambers, J.P.; Berton, M.T.; Arulanandam, B.P. Mast cell TLR2 signaling is crucial for effective killing of Francisella tularensis. J. Immunol. 2012, 188, 5604-5611. [CrossRef]

45. Blanc, L.; Gilleron, M.; Prandi, J.; Song, O.R.; Jang, M.S.; Gicquel, B.; Drocourt, D.; Neyrolles, O.; Brodin, P.; Tiraby, G.; et al. Mycobacterium tuberculosis inhibits human innate immune responses via the production of TLR2 antagonist glycolipids. Proc. Natl. Acad. Sci. USA 2017, 114, 11205-11210. [CrossRef]

46. Jacobs, A.J.; Mongkolsapaya, J.; Screaton, G.R.; McShane, H.; Wilkinson, R.J. Antibodies and tuberculosis. Tuberculosis 2016, 101, 102-113. [CrossRef]

47. Lee, A.Y.S.; Körner, H. The CCR6-CCL20 axis in humoral immunity and T-B cell immunobiology. Immunobiology 2019, 224, 449-454. [CrossRef]

48. Lin, P.L.; Plessner, H.L.; Voitenok, N.N.; Flynn, J.L. Tumor necrosis factor and tuberculosis. J. Investig. Dermatol. Symp. Proc. 2007, 12, 22-25. [CrossRef]

49. Torraca, V.; Tulotta, C.; Snaar-Jagalska, B.E.; Meijer, A.H. The chemokine receptor CXCR4 promotes granuloma formation by sustaining a mycobacteria-induced angiogenesis programme. Sci. Rep. 2017, 7, 45061. [CrossRef]

50. Hoshino, Y.; Tse, D.B.; Rochford, G.; Prabhakar, S.; Hoshino, S.; Chitkara, N.; Kuwabara, K.; Ching, E.; Raju, B.; Gold, J.A.; et al. Mycobacterium tuberculosis-induced CXCR4 and chemokine expression leads to preferential X4 HIV-1 replication in human macrophages. J. Immunol. 2004, 172, 6251-6258. [CrossRef] 
51. Ratajczak, M.Z.; Reca, R.; Wysoczynski, M.; Yan, J.; Ratajczak, J. Modulation of the SDF-1-CXCR4 axis by the third complement component (C3)-implications for trafficking of CXCR4+ stem cells. Exp. Hematol. 2006, 34, 986-995. [CrossRef]

52. Ratajczak, M.Z.; Serwin, K.; Schneider, G. Innate immunity derived factors as external modulators of the CXCL12-CXCR4 axis and their role in stem cell homing and mobilization. Theranostics 2013, 3, 3-10. [CrossRef]

53. Sheerin, N.S.; Zhou, W.; Adler, S.; Sacks, S.H. TNF-alpha regulation of C3 gene expression and protein biosynthesis in rat glomerular endothelial cells. Kidney Int. 1997, 51, 703-710. [CrossRef]

54. De la Fuente, J.; Gortázar, C.; Juste, R. Complement component 3: A new paradigm in tuberculosis vaccine. Expert Rev. Vaccines 2016, 15, 275-277. [CrossRef]

(C) 2020 by the authors. Licensee MDPI, Basel, Switzerland. This article is an open access article distributed under the terms and conditions of the Creative Commons Attribution (CC BY) license (http://creativecommons.org/licenses/by/4.0/). 